\title{
Interaction of Water Vapor with the Surfaces of Imidazolium-Based Ionic Liquid Nanoparticles and Thin Films
}

\author{
Amanda C. MacMillan, Theresa M. McIntire, J. Alfredo Freites, Douglas J. Tobias, \\ and Sergey A. Nizkorodov*
}

Department of Chemistry, University of California, Irvine, Irvine, California 92697-2025, United States
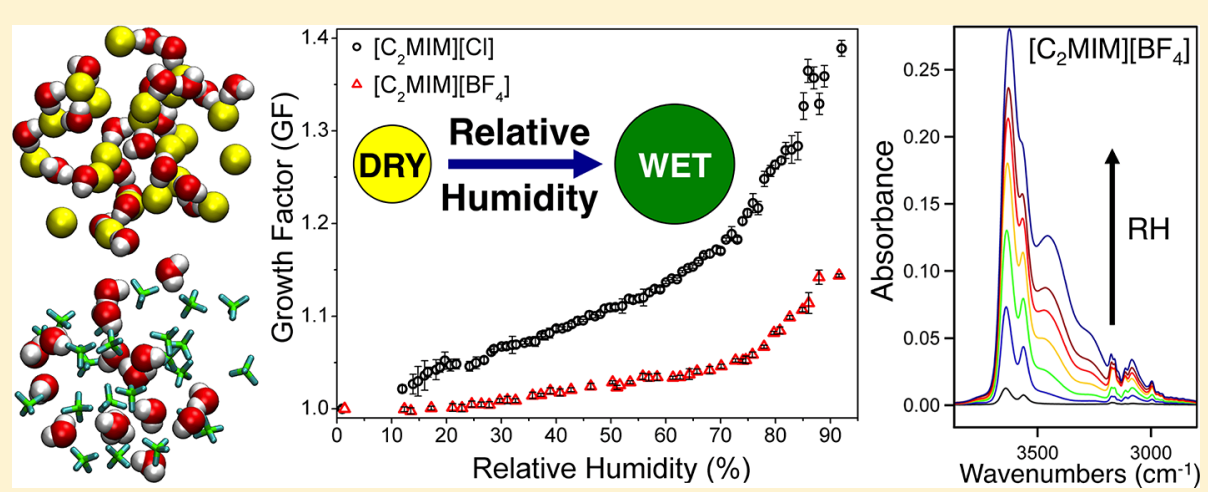

ABSTRACT: Understanding the interactions of humid air with ionic liquids (ILs) is critical for predicting how their physicochemical properties are affected by water. Using experimental and theoretical techniques, water vapor's interaction with aerosolized nanoparticles and thin films of $\left[\mathrm{C}_{2} \mathrm{MIM}\right][\mathrm{Cl}]$ and $\left[\mathrm{C}_{2} \mathrm{MIM}\right]\left[\mathrm{BF}_{4}\right]$ was studied. Solutions were electrosprayed to produce dry particles. Particles' hygroscopic growth was quantified using tandem nanodifferential mobility analysis as a function of relative humidity $(\mathrm{RH})$. This is the first report of the interaction of water with aerosolized IL nanoparticles. The particles' small size allows true IL-water vapor equilibrium achieved quickly. Growth curves for both ILs show steady water uptake with increasing RH. Water vapor uptake by IL thin films was also examined using ATR-FTIR spectroscopy. Both experimental methods show $\left[\mathrm{C}_{2} \mathrm{MIM}\right][\mathrm{Cl}]$ absorbs more water vapor than $\left[\mathrm{C}_{2} \mathrm{MIM}\right]\left[\mathrm{BF}_{4}\right]$ over the entire $\mathrm{RH}$ range. Water molar fractions, calculated from growth curves, agreed well with those estimated from ATR-FTIR data. MD simulations, used to model IL-water interactions, revealed strong interactions between $\left[\mathrm{Cl}^{-}\right]$and water and considerably weaker interactions between $\left[\mathrm{BF}_{4}{ }^{-}\right]$and water. Widths and position of $\mathrm{O}-\mathrm{H}$ stretching vibrations from $\mathrm{MD}$ simulations qualitatively reproduced ATR-FTIR results. These experimental and theoretical data provide a comprehensive picture of the behavior of absorbed water in ILs.

\section{INTRODUCTION}

Ionic liquids (ILs) are salts, typically composed of organic cations and inorganic anions, with melting points around or below 100 ${ }^{\circ} \mathrm{C}$. They represent a large class of molecules that have unique and widely tunable physical and chemical properties. ${ }^{1-3}$ For example, there is a significant interest in the use of ILs in green chemistry, ${ }^{2,4,5}$ due to their negligible vapor pressure at room temperature, ${ }^{6}$ and for many other applications including solvents in synthesis and catalysis, ${ }^{1,6}$ chemical extraction, ${ }^{1,2,5}$ and fuel cells. $^{7}$

Physical properties such as conductivity, viscosity, density, and surface tension of ILs are known to depend on the presence of water, both adsorbed and absorbed. ${ }^{3,8}$ Water is ubiquitous in the environment, and hygroscopic ILs such as those with imidazolium-based cations can uptake significant amounts of water vapor from ambient air, which alters their physical and chemical properties. ${ }^{1,3}$ Thus, quantification of water uptake by hygroscopic ILs and understanding how the presence of water affects the nature of the ion-ion and ion-water interactions are critical for use of ILs in future applications. ${ }^{8-14}$
Numerous experimental and theoretical studies have investigated the interaction of imidazolium-based ILs with water. ${ }^{3,8-35}$ It is understood that both the cation and the anion have an effect on how ILs interact with water, with the anion having a stronger effect. $^{3,17,19}$ Early experimental work by Seddon et al. investigated the miscibility of water with ILs containing 1-nalkyl-3-methylimidazolium ( $\left[\mathrm{C}_{n} \mathrm{MIM}^{+}\right], n=$ number of carbons on the linear alkyl chain) cations and various anions at room temperature. ${ }^{3}$ It was determined that, regardless of the alkyl chain length, all halide anions were fully soluble in water and all hexafluorophosphate $\left(\left[\mathrm{PF}_{6}^{-}\right]\right)$anions were insoluble. ${ }^{3}$ However, alkyl chain length did have an effect on water miscibility of $\left[\mathrm{C}_{n} \mathrm{MIM}^{+}\right]$-based ILs with tetrafluoroborate $\left(\left[\mathrm{BF}_{4}^{-}\right]\right)$anions; for chain lengths of $n=2$ or 4 , the ILs were fully miscible, but for $n>$ 4, the ILs formed biphasic systems. ${ }^{3}$

Cammarata et al. performed early attenuated total reflection (ATR) infrared (IR) studies on the molecular states of water

Received: May 23, 2012

Revised: August 7, 2012

Published: August 17, 2012 
absorbed from the atmosphere in ILs under ambient conditions. $^{19}$ For 1-butyl-3-methylimidazolium tetrafluoroborate $\left(\left[\mathrm{C}_{4} \mathrm{MIM}\right]\left[\mathrm{BF}_{4}\right]\right)$, water interacted mainly with the anions at low water content to create stable hydrogen bonds (H-bonds) to two $\left[\mathrm{BF}_{4}{ }^{-}\right]$anions, via $\left[\mathrm{F}^{-} \cdots \mathrm{H}-\mathrm{O}-\mathrm{H}^{\cdots} \cdot \mathrm{F}^{-}\right]$bridges. $^{19}$ The IR spectra showed two bands at 3640 and $3560 \mathrm{~cm}^{-1}$ characteristic of the water forming H-bonds to the anions; a predominance of these complexes occurred at $\chi_{\mathrm{w}}$ (the molar fraction of water in the $\mathrm{IL}$-water mixture) $<0.2$, while the formation of $\mathrm{H}$-bonded water clusters was favored at $\chi_{\mathrm{w}}>0.3$. However, for more basic anions, such as acetate, one broad band around $3400 \mathrm{~cm}^{-1}$ indicated the preference to form water-water aggregates. ${ }^{19}$ Similarly, more recent ATR-Fourier transform infrared (FTIR) and NMR studies involving the interaction of 1-ethyl-3-methylimidazolium tetrafluoroborate $\left(\left[\mathrm{C}_{2} \mathrm{MIM}\right]\left[\mathrm{BF}_{4}\right]\right)$ and water molecules also observed a significant change in the state of water molecules in $\left[\mathrm{C}_{2} \mathrm{MIM}\right]\left[\mathrm{BF}_{4}\right]$ at $\chi_{\mathrm{w}} \approx 0.3 .^{30}$ In addition, large-angle X-ray scattering experiments showed that as the concentration of water increased in $\left[\mathrm{C}_{2} \mathrm{MIM}\right]\left[\mathrm{BF}_{4}\right]$ solutions, stronger interactions between the $\mathrm{C} 2$ on the ethyl imidazolium ring and the $\left[\mathrm{BF}_{4}{ }^{-}\right]$ anion occur, with a concomitant weakening of interactions at $\mathrm{C} 4$ and C5 (Figure 1a).

(a)

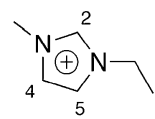

(b)

$$
\mathrm{Cl}^{-} \stackrel{\mathrm{I}}{\mathrm{F}^{\prime \cdots} \mathrm{B}^{-}} \mathrm{F}
$$

Figure 1. Structures of ILs used in this study: (a) 1-ethyl-3methylimidazolium $\left(\left[\mathrm{C}_{2} \mathrm{MIM}^{+}\right]\right)$cations paired with either a chloride $\left(\left[\mathrm{Cl}^{-}\right]\right)$or tetrafluoroborate $\left(\left[\mathrm{BF}_{4}^{-}\right]\right)$anion $(\mathrm{b})$.

Early molecular dynamics (MD) simulations by Hanke et al. on single water molecules and 1,3-dimethylimidazolium chloride $\left(\left[\mathrm{C}_{1} \mathrm{MIM}\right][\mathrm{Cl}]\right)$ found that water interacts predominantly with $\left[\mathrm{Cl}^{-}\right]$in the solution. ${ }^{29}$ The same group investigated $\left[\mathrm{C}_{1} \mathrm{MIM}\right]$ $[\mathrm{Cl}]$-water mixtures and observed that at low water concentrations water is either isolated or contained in small water clusters, but at higher concentrations the water molecules form a continuous network. ${ }^{31}$ They also found that at higher water concentrations the properties of the IL-water mixture were different from the pure IL. ${ }^{31}$ Work by Saha and Hamaguchi using single crystal X-ray diffraction and Raman spectroscopy showed that water has the ability to alter the conformation of the $n$-butyronitrile side chain in 1-butyronitrile-3-methylimidazolium halides and that water participates in a $\mathrm{H}$-bonding network with the anions. ${ }^{21}$ This H-bonding network displaces the anion's position, which disturbs the arrangement and stable molecular structure of the IL. ${ }^{21}$

NMR experiments carried out by Mele et al. gave direct evidence of the existence of tight ion pairs in the pure IL, even with the presence of small amounts of water. ${ }^{20}$ The IL structure is disturbed with a lower degree of ring stacking by cation-mediated $\mathrm{H}$-bonds between water and the imidazolium ion protons. $\mathrm{MD}$ simulations performed by Moreno et al. on $\left[\mathrm{C}_{4} \mathrm{MIM}\right]\left[\mathrm{BF}_{4}\right]-$ water mixtures from 0 to $0.5 \chi_{\mathrm{w}}$ indicated that at low $\chi_{\mathrm{w}}$ the water molecules are selectively coordinated to both the cation and anion, and the ionic network is unperturbed. ${ }^{28}$ However, at higher $\chi_{w}$ they observed the formation of whole water clusters that perturbed the ionic network. Additionally, they found water clusters formed almost entirely from linear chains of $\mathrm{H}$-bonded molecules. Far-IR measurements and density functional calculations by the Ludwig group correlated cation-anion cohesive energies in imidazolium-based ILs; the intermolecular stretching modes shifted to higher energies as the anion ionic strength increased. ${ }^{32,36}$ Recently, cohesive energies and the electron density of H-bonding interactions for imidazoliumbased ILs as a function of anion identity were studied by Gao et al. ${ }^{33}$ Their results showed that water dissolved in ILs weakened the electron density of the $\mathrm{C}-\mathrm{H} \cdots \mathrm{Y}$ bond between the cation and anion. Finally, Dang and Wick performed MD simulations to calculate the potentials of mean force for transporting a water molecule across the air-IL interface in $\left[\mathrm{C}_{4} \mathrm{MIM}\right]\left[\mathrm{BF}_{4}\right]$ and $\left[\mathrm{C}_{4} \mathrm{MIM}\right]\left[\mathrm{PF}_{6}\right]^{35}$ They found that water prefers bulk solvation with no evidence for interfacial energy minima.

While numerous studies of water and ILs have been conducted, few studies have attempted to quantify the amount of water vapor that ILs can absorb from the atmosphere. ${ }^{12,34}$ Previous studies were performed on bulk quantities of ILs. However, there are kinetic limitations associated with studying large quantities of ILs, often taking several hours or longer for bulk ILs to reach equilibrium with water vapor. Work by Cuadrado-Prado et al. studied the change in mass of $1 \mathrm{~mL}$ volumes (initial masses: $\sim 1-2 \mathrm{~g}$ ) of imidazolium-based ILs with $\left[\mathrm{BF}_{4}^{-}\right]$and alkyl sulfate anions after exposure to varying levels of relative humidity $(\mathrm{RH}) .^{34}$ They found that the mass of IL film increased as the $\mathrm{RH}$ increased, though it was incorrectly concluded that water was only adsorbed on the surface, creating a thin film. At $100 \% \mathrm{RH}$, it took from 80 to $100 \mathrm{~h}$ for the ILs to reach an equilibrium with the atmospheric water vapor and become completely saturated (without stirring). ${ }^{34}$ In a similar study, Di Francesco et al. examined the kinetics of water vapor uptake by several ILs at two RH levels, $43 \%$ and $81 \%$ RH, using gravimetric analysis on initial ILs volumes of $2 \mathrm{~mL} .{ }^{12}$ The results showed that the more hydrophilic ILs absorbed more water vapor compared to the more hydrophobic ILs. Their study also took a long time for the ILs to either reach or begin to approach equilibrium with exposed water vapor; anywhere from 20 to $60+$ $\mathrm{h}$ at $43 \% \mathrm{RH}^{12}$ At $81 \% \mathrm{RH}$, equilibrium was reached for most of the ILs after $20 \mathrm{~h}$, while $\left[\mathrm{C}_{4} \mathrm{MIM}\right]\left[\mathrm{BF}_{4}\right]$ took almost $60 \mathrm{~h}$. For both $\mathrm{RH}$ levels, they found that $\left[\mathrm{C}_{4} \mathrm{MIM}\right]\left[\mathrm{BF}_{4}\right]$ took the longest time to reach equilibrium and absorbed the most amount of water, concluding that it was the most hydrophilic of the ILs in their study. ${ }^{12}$

The kinetic limitations associated with large quantities of IL in previous studies of water vapor absorption by imidazolium-based ILs can be circumvented by studying water uptake by IL nanoparticles (a few tens of nanometers in diameter) or thin films (a few micrometers in thickness). Hygroscopic nanoparticles generally achieve equilibrium with water vapor in a fraction of a second. ${ }^{37}$ For the first time, we report on the interaction of $\left[\mathrm{C}_{2} \mathrm{MIM}\right][\mathrm{Cl}]$ and $\left[\mathrm{C}_{2} \mathrm{MIM}\right]\left[\mathrm{BF}_{4}\right]$ IL nanoparticles with water absorbed from the vapor phase using hygroscopicity measurements. By aerosolizing ILs and comparing their dry sizes to their wet sizes, we can quantitatively determine the amount of water that particles can take up from humidified air over a broad range of $\mathrm{RH}$. In addition, ATR-FTIR spectra of thin films of $\left[\mathrm{C}_{2} \mathrm{MIM}\right][\mathrm{Cl}]$ and $\left[\mathrm{C}_{2} \mathrm{MIM}\right]\left[\mathrm{BF}_{4}\right]$ are measured, and the $\mathrm{C}-\mathrm{H}$ and $\mathrm{O}-\mathrm{H}$ band positions and intensities are determined as a function of $\mathrm{RH}$ in order to provide information about the nature of interactions between ILs and water molecules. We also carry out MD simulations of equimolar IL-water mixtures to aid in the interpretation of experimental data. These experimental and theoretical data, in combination, provide a comprehensive picture of the behavior of absorbed water in ILs. 


\section{EXPERIMENTAL AND COMPUTATIONAL METHODS}

ILs Used in the Study. The sources and purities of the ILs were as follows: 1-ethyl-3-methylimidazolium chloride $\left(\left[\mathrm{C}_{2} \mathrm{MIM}\right][\mathrm{Cl}]\right)$ (Aldrich, 98\%) and 1-ethyl-3-methylimidazolium tetrafluoroborate $\left(\left[\mathrm{C}_{2} \mathrm{MIM}\right]\left[\mathrm{BF}_{4}\right]\right)$ (Aldrich, 98\%). Their chemical structures are shown in Figure 1. Every attempt was made to keep the ILs as water-free as possible. All samples were prepared in a drybox that was continuously purged with dry air. All chemicals were sealed with a paraffin film and stored in a desiccator when not in use. $\left[\mathrm{C}_{2} \mathrm{MIM}\right]\left[\mathrm{BF}_{4}\right]$ was protected from light by wrapping glassware in foil and stored in dark, amber bottles to prevent potential photodegradation.

IL Purification. ILs were purified and dried before all experiments using standard literature techniques. ${ }^{1,38-40}$ $\left[\mathrm{C}_{2} \mathrm{MIM}\right][\mathrm{Cl}]$ was washed several times with ethyl acetate (Acros Organics, 99.5\% Spectroscopy grade) and vacuum-dried at $\sim 363 \mathrm{~K}$ for $48 \mathrm{~h}^{38-40}\left[\mathrm{C}_{2} \mathrm{MIM}\right]\left[\mathrm{BF}_{4}\right]$ was stirred with activated carbon (Sigma-Aldrich, 20-40 mesh) for $12 \mathrm{~h}$, filtered with a short column of neutral, activated alumina (Fisher, 60$325 \mathrm{mesh}$ ), and vacuum-dried at $\sim 343 \mathrm{~K}$ for 48 h. ${ }^{1,40}$

${ }^{1} \mathrm{H}$ NMR Spectroscopy. ILs purities were verified before and after purification and drying with ${ }^{1} \mathrm{H}$ NMR spectroscopy, using a Bruker DRX500 equipped with a TCI cryoprobe at $298 \mathrm{~K}$ using acetone- $d_{6}$ (Cambridge Isotope Laboratories, Inc.; D, 99.9\%, with $1 \% \mathrm{v} / \mathrm{v}$ TMS) as the solvent.

IL Water Content. After vacuum drying, the amount of water left in the ILs was measured using a Karl Fischer titrator (Mettler Toledo, Model DL39) with analyte hydranal coulomat A and catholyte hydranal coulomat CG (both from Fluka). For $\left[\mathrm{C}_{2} \mathrm{MIM}\right][\mathrm{Cl}]$, a solution was prepared by diluting $\sim 0.6 \mathrm{~g}$ of the IL into $\sim 1 \mathrm{~mL}$ of anhydrous methanol $(\mathrm{MeOH})$. Anhydrous $\mathrm{MeOH}$ was prepared by sparging with argon and then dried with columns containing Q-5 (supported redox catalyst to remove dioxygen) and molecular sieves. For $\left[\mathrm{C}_{2} \mathrm{MIM}\right]\left[\mathrm{BF}_{4}\right]$, neat samples were examined. The water contents of $\left[\mathrm{C}_{2} \mathrm{MIM}\right][\mathrm{Cl}]$ and $\left[\mathrm{C}_{2} \mathrm{MIM}\right]\left[\mathrm{BF}_{4}\right]$, averaged over 3-4 measurements of the solutions and neat samples, were $\sim 390$ and $\sim 120 \mathrm{ppm}$, respectively, by mass. The water content of the anhydrous $\mathrm{MeOH}$ solvent was $\sim 180$ ppm using Karl Fischer titration.

IL Nanoparticle Generation. IL solutions used for electrospray (ES) were prepared by dilution of the purified and dried IL, as described above, in anhydrous $\mathrm{MeOH}$ to reach a final solution concentration of $\sim 0.5-0.6 \mathrm{~g} \mathrm{~L}^{-1}$. All solutions were stored in dark, amber vials that were closed with septum caps, sealed with a paraffin film, and stored in a desiccator when not in use. Solutions were electrosprayed at $295 \mathrm{~K}$ using a custom-built ES aerosol generator (EAG). ${ }^{41,42}$ Solutions were withdrawn from the vial directly using a syringe (Hamilton GT, $1 \mathrm{~mL}$ ) to avoid water uptake from the atmosphere. A syringe pump (Model 780100, KD Scientific), with a flow rate of $0.15 \mathrm{~mL} \mathrm{~h}^{-1}$, was used to push the solutions through a $5 \mathrm{~cm}$ long, quartz capillary tube (inner diameter (i.d.) $100 \mu \mathrm{m}$, outer diameter (o.d.) $360 \mu \mathrm{m}$ ). The capillary was housed in a $5 \mathrm{~cm}^{3}$ chamber that was equipped with glass windows, a microscope objective, and a $\mathrm{CCD}$ camera for viewing the spray (Figure $2 \mathrm{a}, \mathrm{b}$ ). A stable conejet (Taylor cone) of the solution was generated by applying a $\sim 3$ $\mathrm{kV}$ potential directly to the stainless steel union, which connected the capillary and syringe. The capillary tip was positioned $\sim 7-8$ $\mathrm{mm}$ away from a bipolar neutralizer (either ${ }^{85} \mathrm{Kr} 10 \mathrm{mCi}$ TSI Model 3077A or ${ }^{210}$ Po $10 \mathrm{mCi}$ NRD Model P-2021). Nanoparticles were carried with a flow of dry air $(<1 \% \mathrm{RH})$, at a flow rate of $\sim 0.8$ SLM (standard liters per minute), toward the

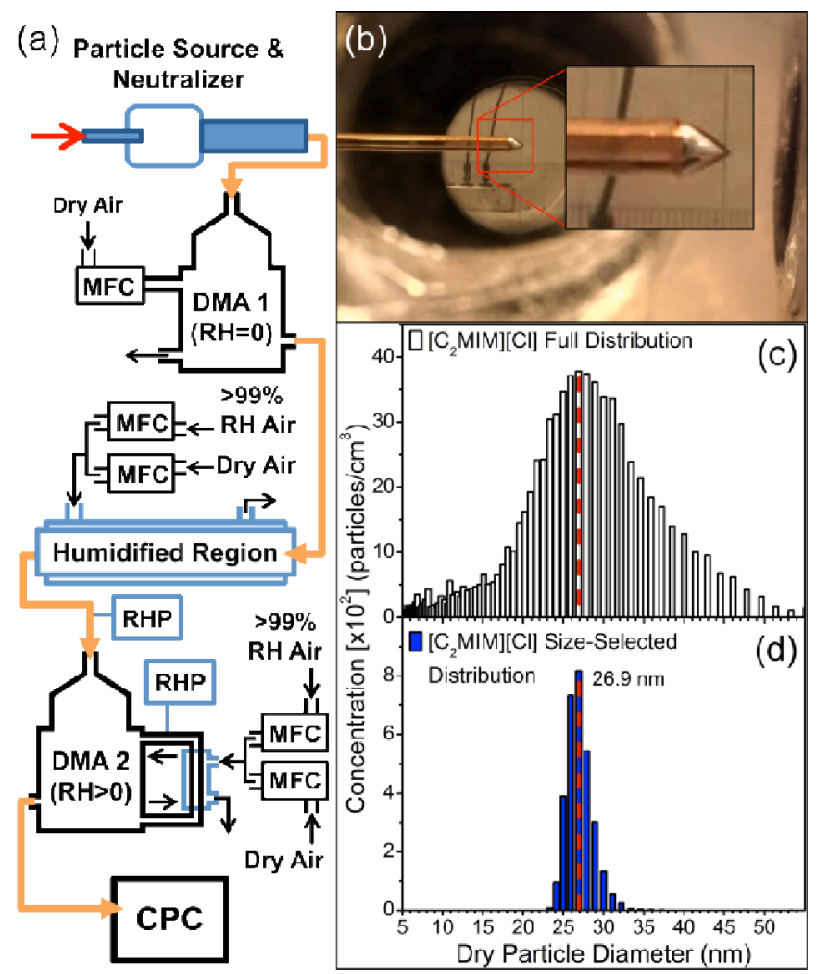

Figure 2. (a) Schematic diagram of the apparatus used for IL nanoparticle hygroscopic growth measurements. Key: DMA, differential mobility analyzer; RHP, relative humidity probe; CPC, condensation particle counter; MFC, mass flow controller. (b) An image of the Taylor cone for an electrosprayed solution of $\left[\mathrm{C}_{2} \mathrm{MIM}\right][\mathrm{Cl}]$ with an inset, magnified image of the quartz capillary tube (o.d. $360 \mu \mathrm{m}$ ) and Taylor cone. (c) Full particle mobility size distribution of the dry $\left[\mathrm{C}_{2} \mathrm{MIM}\right][\mathrm{Cl}]$ particles measured by DMA1. (d) The mobility size distribution after size selection for $26.9 \pm 0.01 \mathrm{~nm}\left[\mathrm{C}_{2} \mathrm{MIM}\right][\mathrm{Cl}]$ particles measured by DMA2. The red, dotted line in panels $\mathrm{c}$ and $\mathrm{d}$ indicates where the dry particle distributions were centered (at $26.9 \mathrm{~nm}$ ).

electrically grounded neutralizer opening. The ES was operated continuously and generated a dry, polydisperse number concentration of particles on the order of $10^{5}$ particles $\mathrm{cm}^{-3}$, with sizes ranging from $\sim 5$ to $55 \mathrm{~nm}$ (Figure $2 \mathrm{c}$ ). The narrow size distribution of particles was selected from this polydisperse population of particles (Figure 2d). The particles' sizes in this study are considerably larger than the 1-7 nm IL nanodroplets investigated by de la Mora and co-workers, which were also generated by an ES method. ${ }^{43-46}$ The differences in the observed particles' size distributions were likely due to the significantly different EAG operation conditions. The IL particles produced in the de la Mora experiments were not neutralized immediately after the ES process, making them more susceptible to Coulomb fission. Prompt neutralization in the present experiments effectively removed charge from the primary droplets to prevent them from fissioning into smaller progeny droplets, resulting in larger residue particles.

IL Hygroscopic Growth Measurements. IL nanoparticle hygroscopicity was determined using tandem nanodifferential mobility analysis (TDMA). ${ }^{47}$ The experimental schematic is shown in Figure 2 a. Under dry conditions ( $<1 \% \mathrm{RH})$, a narrow size distribution of nanoparticles was selected by applying a fixed negative dc potential $(\sim-320 \mathrm{~V})$ to the first differential mobility analyzer (DMA1, TSI Model 3085). Dry IL particles with mobility-equivalent diameters centered at $26.9 \pm 0.1 \mathrm{~nm}$ were selected with geometric standard deviations of $\sim 1.06$ (the stated 
uncertainty of $\pm 0.1 \mathrm{~nm}$ refers to the reproducibility of the average diameter, not to the width of the size-selected distribution, which was $\sim 4 \mathrm{~nm}$ fwhm). As demonstrated by Rader and McMurry, the interpretation of TDMA measurements is simplified considerably if the particle number concentrations do not vary significantly over the size selection window of DMA1. ${ }^{47}$ The size of $26.9 \mathrm{~nm}$ was specifically chosen because it neared the maximum of the full size distribution for the particles generated by the EAG, thus maximizing the particle count (Figure 2b,c) and minimizing the variation in the particle number concentrations across the DMA1 selection window. While the initial particle size selected in this work was fixed, it would be interesting to conduct similar experiments with variable particle sizes in the future, especially in the sub-10 $\mathrm{nm}$ size range, where significant size effects on hygroscopicity can be expected.

Dry IL nanoparticles were then exposed to humidified air by sending them through a Nafion tube (PermaPure). Controlled humid air flowing around the Nafion tube provided the source of $\mathrm{RH}$. RH was maintained by mixing different proportions of wet $(\mathrm{RH}>99 \%)$ and dry $(\mathrm{RH}<1 \%)$ air. $\mathrm{RH}$ and temperature were monitored using Vaisala HMP237 RH probes and a LabVIEW program. The probe humidity accuracy was $\pm 2 \% \mathrm{RH}(0-90 \%$ $\mathrm{RH})$ and $\pm 3 \% \mathrm{RH}(90-100 \% \mathrm{RH})$, while the precision was about $\pm 0.1 \%$ RH. Each probe was calibrated by taking measurements over saturated solutions of $\mathrm{MgCl}_{2}, \mathrm{NaCl}$, and $\mathrm{K}_{2} \mathrm{SO}_{4}$, with a second- or third-order polynomial fit used to interpolate the dependence of the probe response on $\mathrm{RH}$. After particles exited the humidified region, a second DMA (DMA2, TSI Model 3085) was used to measure the particle size distribution of the wet particle size. DMA2 was operated in a scanning mobility particle sizer (SMPS) mode, wherein the potential applied to the central rod was scanned using an electrostatic classifier (TSI Model 3080) controlled by TSI Aerosol Instrument Manager software (version 9.0). A condensation particle counter (CPC, TSI Model 3025A) was used to detect particles from either DMA.

ATR Crystals. Zinc selenide (ZnSe) ATR crystals $(80 \mathrm{~mm} \times$ $10 \mathrm{~mm} \times 4 \mathrm{~mm}$, Pike Technologies or Balboa Scientific), set up for 10 reflections along the length of the crystal, were used as received. Prior to each use, the ATR crystals were cleaned by sequential sonication in ethanol (EMD, OmniSolv, 99.99\%) and acetone (EMD, OmniSolv, 99.84\%). To remove any trace organics that remained, the ATR crystal was placed in an argon plasma discharge (Harrick Plasma Cleaner/Sterilizer PDC-32G, low or medium power, Harrick Scientific Products, Inc.) for $\sim 30$ min, rinsed with ultrapure (Milli-Q) water $(18 \mathrm{M} \Omega \mathrm{cm})$, and dried with nitrogen (UHP, 99.999\%, Oxygen Services).

FTIR Spectroscopy Measurements. Solutions for FTIR were prepared by dissolving the purified and dried ILs in anhydrous $\mathrm{MeOH}$ (final solution concentration of $\sim 0.5-0.6 \mathrm{~g}$ $\mathrm{L}^{-1}$; to resemble the solutions used for ES), ultrapure water, or a mixture of ultrapure water in excess $\mathrm{D}_{2} \mathrm{O}\left(\mathrm{H}_{2} \mathrm{O} / \mathrm{D}_{2} \mathrm{O}\right) \cdot \mathrm{H}_{2} \mathrm{O}$ / $\mathrm{D}_{2} \mathrm{O}$ solutions, as described in Smith et al., ${ }^{48}$ were prepared using ultrapure water and $\mathrm{D}_{2} \mathrm{O}$ (Cambridge Isotope Laboratories, Inc., 99.96\%). IL-water and $\mathrm{IL}-\mathrm{H}_{2} \mathrm{O} / \mathrm{D}_{2} \mathrm{O}$ solutions were prepared in 1:1 molar ratios. Thin films of purified ILs (neat or in $\mathrm{MeOH}$, water, or $\mathrm{H}_{2} \mathrm{O} / \mathrm{D}_{2} \mathrm{O}$ solutions) were applied to clean $\mathrm{ZnSe}$ ATR substrates by drop deposition. In some cases, aliquots of the final solutions were sprayed onto the clean ATR crystal using a small nebulizer (artist's airbrush), as previously described. ${ }^{49,50}$ The ILcoated ATR crystal was immediately placed into a trough plate flow-through multiple reflection horizontal ATR cell (Pike Technologies) situated in the platform optics assembly within the sampling compartment of the FTIR spectrometer. A flow of dry nitrogen (UHP) was introduced into the ATR cell overnight to drive off the solvent and water absorbed during film preparation.

IR spectra were acquired using a Nicolet 6700 FTIR spectrometer (now Thermo Electron Corporation) equipped with a $\mathrm{KBr}$ beam splitter and a high-temperature ceramic source. FTIR spectra were acquired as single beams at $4 \mathrm{~cm}^{-1}$ resolution with a liquid nitrogen-cooled mercury cadmium telluride detector (MCT-A). A background scan was recorded under the condition of dried flow, described above, for both ILs. The extent of water uptake was monitored using ATR-FTIR. Thin films of $\left[\mathrm{C}_{2} \mathrm{MIM}\right][\mathrm{Cl}]$ and $\left[\mathrm{C}_{2} \mathrm{MIM}\right]\left[\mathrm{BF}_{4}\right]$ were exposed to water vapor in the ATR cell as a function of $\mathrm{RH}$ at $295 \mathrm{~K}$. The spectra were calculated as $-\log \left(S / S_{0}\right)$, where $S_{0}$ is the single beam intensity of the clean ZnSe ATR crystal and $S$ is that of the dry IL. For humidified spectra, the RH inside the ATR cell was first allowed to equilibrate at the RH of interest, and then several spectra were recorded to ensure that IL-water equilibrium was reached (this typically took $\sim 20 \mathrm{~min}$ ). Spectra of IL-water or $\mathrm{IL}-\mathrm{H}_{2} \mathrm{O} / \mathrm{D}_{2} \mathrm{O}$ solutions were recorded under dry $\mathrm{RH}$ conditions in the ATR cell.

MD Simulations. The simulation systems consisted of 512 $\left[\mathrm{C}_{2} \mathrm{MIM}^{+}\right], 512$ anions $\left(\left[\mathrm{Cl}^{-}\right]\right.$or $\left.\left[\mathrm{BF}_{4}^{-}\right]\right)$, and 512 water molecules. Initially, ions and water molecules were placed on a cubic lattice and subjected to 200 steps of conjugate-gradient energy minimization, $2 \mathrm{~ns}$ MD simulation at constant volume and temperature $(373 \mathrm{~K})$, and $4 \mathrm{~ns} \mathrm{MD}$ simulation at constant pressure (500 bar) and temperature $(373 \mathrm{~K})$. The final segments of the $\left[\mathrm{C}_{2} \mathrm{MIM}\right][\mathrm{Cl}]$ and $\left[\mathrm{C}_{2} \mathrm{MIM}\right]\left[\mathrm{BF}_{4}\right]$ trajectories were run at a constant pressure of 1 bar and temperature of $373 \mathrm{~K}$ for 31.6 and $26 \mathrm{~ns}$, respectively. Simulations were performed with the NAMD $2.8 \mathrm{~b} 1$ software package. ${ }^{51}$ The force field of de Andrade et al. ${ }^{52}$ was used for the $\left[\mathrm{C}_{2} \mathrm{MIM}^{+}\right]$and $\left[\mathrm{BF}_{4}{ }^{-}\right]$ions, the force field of Beglov and Roux ${ }^{53}$ was used for $\left[\mathrm{Cl}^{-}\right]$, and the SPC/E model $^{54}$ was used for water. The smooth particle mesh Ewald method $^{55,56}$ was used to calculate electrostatic interactions. Short-range real-space interactions were cut off at $11 \AA$, employing a switching function. A reversible multiple time-step algorithm ${ }^{57}$ was employed to integrate the equations of motion with a time step of 2 fs for electrostatic forces, 1 fs for short-range nonbonded forces, and 1 fs for bonded forces. Snapshots were saved at 1 ps intervals for detailed analysis. All bond lengths involving hydrogen atoms were held fixed using the SHAKE ${ }^{58}$ and SETTLE ${ }^{59}$ algorithms. A Langevin dynamics scheme was used for temperature control, and a Nosé-Hoover-Langevin piston was used for pressure control. ${ }^{60,61}$ Molecular graphics and trajectory analyses were performed using VMD $1.9^{62}$ over the last $10 \mathrm{~ns}$ of each trajectory. The electric field and frequency distribution calculations were performed using the methods described by Smith et al. ${ }^{63}$

\section{RESULTS AND DISCUSSION}

Hygroscopic Growth of IL Nanoparticles. The measured hygroscopic growth curves (from $\sim 0$ to $92 \% \mathrm{RH}$ ) for $\left[\mathrm{C}_{2} \mathrm{MIM}\right][\mathrm{Cl}]$ and $\left[\mathrm{C}_{2} \mathrm{MIM}\right]\left[\mathrm{BF}_{4}\right]$ nanoparticles with initial mobility-equivalent diameters of $26.9 \pm 0.1 \mathrm{~nm}$ are shown in Figure 3. Growth curves were obtained by plotting the measured growth factor (GF) as a function of $\mathrm{RH}$ (eq 1)

$$
\mathrm{GF}(\mathrm{RH})=\frac{d_{\mathrm{m}, \mathrm{wet}}(\mathrm{RH})}{d_{\mathrm{m}, \mathrm{dry}}}
$$




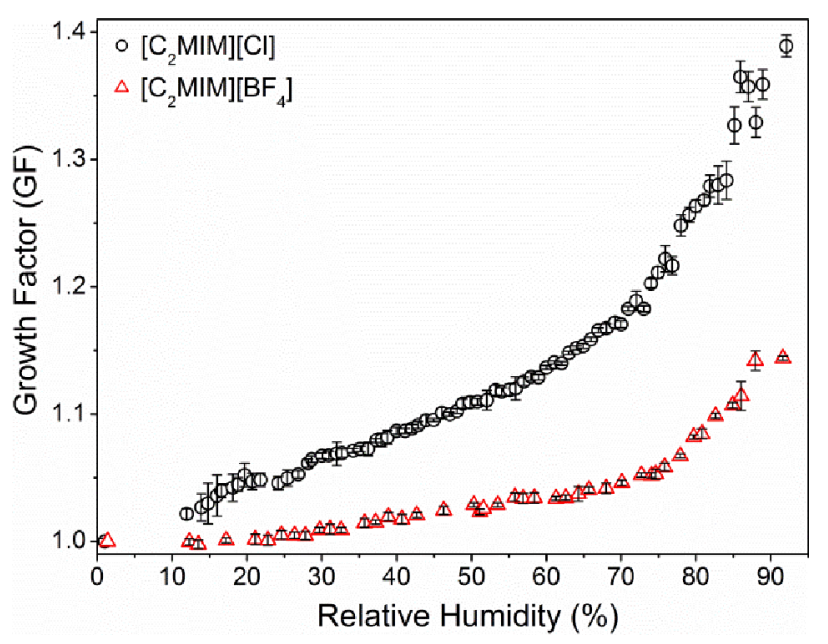

Figure 3. Hygroscopic growth curve of mobility-equivalent diameter selected $26.9 \pm 0.1 \mathrm{~nm}$ particles of $\left[\mathrm{C}_{2} \mathrm{MIM}\right][\mathrm{Cl}]$ (circles) and $\left[\mathrm{C}_{2} \mathrm{MIM}\right]\left[\mathrm{BF}_{4}\right]$ (triangles). Both ILs undergo a gradual increase in growth factor $(\mathrm{GF})$ as the $\mathrm{RH}$ is increased. $\left[\mathrm{C}_{2} \mathrm{MIM}\right][\mathrm{Cl}]$ has a larger GF compared to $\left[\mathrm{C}_{2} \mathrm{MIM}\right]\left[\mathrm{BF}_{4}\right]$ and thus takes up more water.

where $d_{\mathrm{m}, \text { wet }}(\mathrm{RH})$ is the mobility-equivalent diameter of the particles in equilibrium with water vapor at a given $\mathrm{RH}$ and $d_{\mathrm{m} \text {,dry }}$ is the mobility-equivalent diameter of the particles under dry conditions. Growth curves were constructed from a large number of separate experiments, with each experimental run typically spanning $10-30 \% \mathrm{RH}$ units and taking about 1 day to complete. All available GF values were then averaged into 1 and $3 \%$ RH bins for $\left[\mathrm{C}_{2} \mathrm{MIM}\right][\mathrm{Cl}]$ and $\left[\mathrm{C}_{2} \mathrm{MIM}\right]\left[\mathrm{BF}_{4}\right]$, respectively, with each bin typically containing $\geq 12$ measurements from several independent experimental runs. The $95 \%$ confidence intervals in Figure 3 illustrate the degree of reproducibility of these measurements. For both IL growth curves, the data become less reproducible at $\mathrm{RH}$ values $>85 \%$ due to the high sensitivity of $\mathrm{RH}$ to temperature at these high $\mathrm{RH}$ values.

The nanoparticles were exposed to $\mathrm{RH}$ for a period of a few seconds in these experiments. To ensure equilibrium was reached on this time scale, additional measurements were performed wherein the $\left[\mathrm{C}_{2} \mathrm{MIM}\right][\mathrm{Cl}]$ and $\left[\mathrm{C}_{2} \mathrm{MIM}\right]\left[\mathrm{BF}_{4}\right]$ nanoparticles were exposed to $\mathrm{RH}$ for a longer time of $\sim 70 \mathrm{~s}$. Increasing the interaction time did not change the GF values, suggesting that equilibrium was established after only a few seconds of exposure. The rapid establishment of equilibrium with water is a key advantage of the nanoparticle hygroscopic growth measurements compared to experiments with bulk ILs.

As shown in Figure 3, there is a gradual increase in the uptake of water vapor with increasing $\mathrm{RH}$ for both $\left[\mathrm{C}_{2} \mathrm{MIM}\right][\mathrm{Cl}]$ and $\left[\mathrm{C}_{2} \mathrm{MIM}\right]\left[\mathrm{BF}_{4}\right]$. Over the entire $\mathrm{RH}$ range, $\left[\mathrm{C}_{2} \mathrm{MIM}\right][\mathrm{Cl}]$ absorbs more water and has a larger GF compared to $\left[\mathrm{C}_{2} \mathrm{MIM}\right]\left[\mathrm{BF}_{4}\right]$. At the highest $\mathrm{RH}$ value used for both ILs, $\sim 92 \% \mathrm{RH}$, the GFs of $\left[\mathrm{C}_{2} \mathrm{MIM}\right][\mathrm{Cl}]$ and $\left[\mathrm{C}_{2} \mathrm{MIM}\right]\left[\mathrm{BF}_{4}\right]$ are $1.39 \pm 0.01$ and $1.14 \pm 0.01$, corresponding to an increase in particle volume due to water uptake by a factor of 2.69 and 1.48 , respectively. Furthermore, $\left[\mathrm{C}_{2} \mathrm{MIM}\right][\mathrm{Cl}]$ is considerably more efficient at uptake of water vapor at low RH. For example, at $20 \%$ $\mathrm{RH}$, there is no noticeable growth of $\left[\mathrm{C}_{2} \mathrm{MIM}\right]\left[\mathrm{BF}_{4}\right]$, while the diameter of $\left[\mathrm{C}_{2} \mathrm{MIM}\right][\mathrm{Cl}]$ increases by $5 \%(\mathrm{GF} \sim 1.05)$.

It should be noted that TDMA classifies particles by their mobility-equivalent diameter, which is equal to the true diameter only when the particles are homogeneous and spherical. For nonspherical or heterogeneous particles, a shape-dependent correction to the GF is required. ${ }^{64-66}\left[\mathrm{C}_{2} \mathrm{MIM}\right]\left[\mathrm{BF}_{4}\right]$ is a liquid at room temperature, and it remains liquid when it is mixed with water; its nanoparticles, in an aerosolized form, should adopt a spherical shape under all RH conditions. Indeed, work by Larriba et al. on mobility of charged $\left[\mathrm{C}_{2} \mathrm{MIM}\right]\left[\mathrm{BF}_{4}\right]$ clusters showed that they were well described as spheres with effective densities similar to that of bulk $\left[\mathrm{C}_{2} \mathrm{MIM}\right]\left[\mathrm{BF}_{4}\right]$ for cluster sizes in excess of $1.5 \mathrm{~nm}^{46}\left[\mathrm{C}_{2} \mathrm{MIM}\right][\mathrm{Cl}]$ is a solid at room temperature, but it becomes a liquid when mixed with even small amounts of water. The shape of the $\left[\mathrm{C}_{2} \mathrm{MIM}\right][\mathrm{Cl}]$ growth curve suggests that the $\left[\mathrm{C}_{2} \mathrm{MIM}\right][\mathrm{Cl}]$ nanoparticles generated by the ES source are either spherical or close to spherical in shape (water-induced restructuring would make the apparent GF be $<1$ at low $\mathrm{RH}$ otherwise). ${ }^{8-69}$ Therefore, we expect that the $\left[\mathrm{C}_{2} \mathrm{MIM}\right][\mathrm{Cl}]$ particles remain spherical throughout the entire $\mathrm{RH}$ range, and the GF data in Figure 3 reflect the actual increase in the particle diameter. The average GF values for $\left[\mathrm{C}_{2} \mathrm{MIM}\right]\left[\mathrm{BF}_{4}\right]$ are slightly lower than 1 at $\mathrm{RH}<20 \%$; however, the error bars encompass the $\mathrm{GF}=1.00$ value.

In contrast to the smooth increase in GF with RH for the IL nanoparticles, hygroscopic growth curves of typical inorganic, ionic compounds have well-defined deliquescence phase transitions that manifest themselves as an abrupt change in the $\mathrm{GF}$ at a certain $\mathrm{RH}$ value. For example, $\mathrm{NaCl}$ and $\left(\mathrm{NH}_{4}\right)_{2} \mathrm{SO}_{4}$ deliquesce around $\sim 75 \%$ and $\sim 80 \% \mathrm{RH}$, respectively. No evidence for phase transitions was observed for either $\mathrm{IL}$ in this study (Figure 3). The absence of a phase transition for $\left[\mathrm{C}_{2} \mathrm{MIM}\right][\mathrm{Cl}]$ is surprising, considering that it is a solid at room temperature. If a water vapor induced solid-to-liquid phase transition does occur in $\left[\mathrm{C}_{2} \mathrm{MIM}\right][\mathrm{Cl}]$, it must do so without a significant change in the particle size. The smooth increase in the GF with RH is more reminiscent of the behavior of particles composed of hygroscopic liquids. For example, the growth curve for $\mathrm{H}_{2} \mathrm{SO}_{4}$ particles, with $d_{\mathrm{m}, \mathrm{dry}}=\sim 30 \mathrm{~nm}$, depicts a smooth increase in wet particle size as RH increases, with a GF of $\sim 1.6$ at $80 \% \mathrm{RH}^{70}$

Although the imidazolium ILs are regarded as hygroscopic, their GFs are actually small in comparison with inorganic salts. For example, Biskos et al. performed systematic measurements of GFs of pure $\mathrm{NaCl}$ nanoparticles of different sizes. ${ }^{68}$ At $80 \% \mathrm{RH}$, $\mathrm{NaCl}$ particles with $d_{\mathrm{m}, \text { dry }}=30 \mathrm{~nm}$ had a larger GF of $1.60^{68}$ compared to $1.26 \pm 0.01$ for $\left[\mathrm{C}_{2} \mathrm{MIM}\right][\mathrm{Cl}]$ and $1.08 \pm 0.01$ for $\left[\mathrm{C}_{2} \mathrm{MIM}\right]\left[\mathrm{BF}_{4}\right]$. In a separate study, Biskos et al. examined the hygroscopicity of pure $\left(\mathrm{NH}_{4}\right)_{2} \mathrm{SO}_{4}$ particles with $d_{\mathrm{m} \text {,dry }}$ values of 20 and $40 \mathrm{~nm} .{ }^{69}$ At $80 \% \mathrm{RH}$, the 20 and $40 \mathrm{~nm}\left(\mathrm{NH}_{4}\right)_{2} \mathrm{SO}_{4}$ particles had GFs of $\sim 1.40,{ }^{69}$ well in excess of the corresponding GF values of the ILs shown in Figure 3.

ATR-FTIR Spectra of ILs. The IR spectra of purified, dry $\left[\mathrm{C}_{2} \mathrm{MIM}\right][\mathrm{Cl}]$ and $\left[\mathrm{C}_{2} \mathrm{MIM}\right]\left[\mathrm{BF}_{4}\right]$ on ZnSe ATR crystals are shown in Figures $4 \mathrm{a}$ and $5 \mathrm{a}$, respectively. The spectra are calculated as $-\log \left(S / S_{0}\right)$, where $S_{0}$ is the IR beam intensity penetrating through the clean $\mathrm{ZnSe}$ ATR crystal and $S$ is the beam intensity penetrating through the crystal coated with a thin film of dry IL. The spectra are consistent with previous IR studies of these ILs. ${ }^{71-81}$ Spectral bands in the region from 3200 to 3000 $\mathrm{cm}^{-1}$ are attributed to the coupled aromatic ring $\mathrm{C}-\mathrm{H}$ stretching vibrations of the imidazolium hydrogen atoms, while those between 3000 and $2850 \mathrm{~cm}^{-1}$ can be assigned to the aliphatic $\mathrm{C}-\mathrm{H}$ stretches of the $\mathrm{CH}_{2}$ and $\mathrm{CH}_{3}$ groups of the ethyl chain and of the $\mathrm{CH}_{3}$ group bonded directly to the $\left[\mathrm{C}_{2} \mathrm{MIM}^{+}\right]$ring. ${ }^{71-78,81}$ In the spectrum of the dry $\left[\mathrm{C}_{2} \mathrm{MIM}\right][\mathrm{Cl}]$ salt (Figure $4 \mathrm{a}$ ), the band at ca. $3048 \mathrm{~cm}^{-1}$ is the so-called " $\left[\mathrm{Cl}^{-}\right]$interaction band", characteristic of stretching vibrations of $\mathrm{C} 2-\mathrm{H}$ and $\mathrm{C} 4-\mathrm{H}$ or 

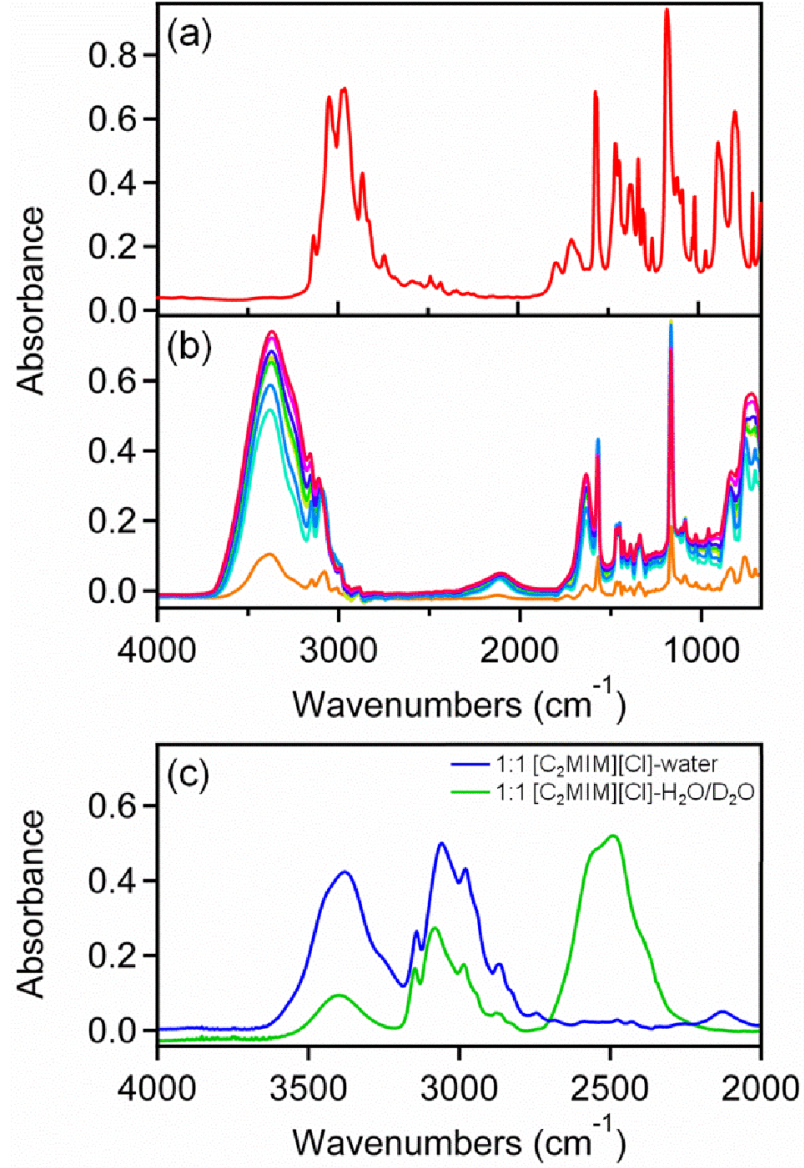

Figure 4. (a) ATR-FTIR spectra of dry $\left[\mathrm{C}_{2} \mathrm{MIM}\right][\mathrm{Cl}]$ on $\mathrm{ZnSe}$. (b) ATR-FTIR spectra of $\left[\mathrm{C}_{2} \mathrm{MIM}\right][\mathrm{Cl}]$ after exposure to increasing $\mathrm{RH}$ values of $4,15,27,43,49,58,72$, and $79 \%$ (the background contribution from the dry $\left[\mathrm{C}_{2} \mathrm{MIM}\right][\mathrm{Cl}]$ was subtracted). (c) ATR-FTIR spectra of 1:1 $\left[\mathrm{C}_{2} \mathrm{MIM}\right][\mathrm{Cl}]$-water and 1:1 $\left[\mathrm{C}_{2} \mathrm{MIM}\right][\mathrm{Cl}]-\mathrm{H}_{2} \mathrm{O} / \mathrm{D}_{2} \mathrm{O}$ mixtures on $\mathrm{ZnSe}$.

$\mathrm{C} 5-\mathrm{H}$ bonds interacting with the $\left[\mathrm{Cl}^{-}\right]$anion. ${ }^{75,79,80}$ The dry $\left[\mathrm{C}_{2} \mathrm{MIM}\right]\left[\mathrm{BF}_{4}\right]$ spectrum (Figure $5 \mathrm{a}$ ) exhibits similar $\mathrm{C}-\mathrm{H}$ stretching bands at 3165 and $3123 \mathrm{~cm}^{-1}$ attributed to bonding of $\left[\mathrm{BF}_{4}^{-}\right]$with $\mathrm{C} 4-\mathrm{H}$ (or $\mathrm{C} 5-\mathrm{H}$ ) and $\mathrm{C} 2-\mathrm{H}$, respectively. ${ }^{71,81}$ Prominent imidazolium ring stretching modes are seen at 1572 and $1172 \mathrm{~cm}^{-1}$ for $\left[\mathrm{C}_{2} \mathrm{MIM}\right][\mathrm{Cl}]^{75}$ and 1576 and $1171 \mathrm{~cm}^{-1}$ for $\left[\mathrm{C}_{2} \mathrm{MIM}\right]\left[\mathrm{BF}_{4}\right]^{71,72}$ Stretching modes of the $\left[\mathrm{BF}_{4}^{-}\right]$anion (Figure $5 \mathrm{a}$ ) are the sharp peaks around $1286 \mathrm{~cm}^{-1}$ and at 755 $\mathrm{cm}^{-1}$ and the broad peak centered at ca. $1070 \mathrm{~cm}^{-1} .71,72$

Figures $4 \mathrm{~b}$ and $5 \mathrm{~b}$ show the IR spectra of $\left[\mathrm{C}_{2} \mathrm{MIM}\right][\mathrm{Cl}]$ and $\left[\mathrm{C}_{2} \mathrm{MIM}\right]\left[\mathrm{BF}_{4}\right]$, respectively, after exposure to water vapor at various levels of $\mathrm{RH}$. The extent of water uptake was monitored using ATR-FTIR by exposure of $\left[\mathrm{C}_{2} \mathrm{MIM}\right][\mathrm{Cl}]$ and $\left[\mathrm{C}_{2} \mathrm{MIM}\right]$ $\left[\mathrm{BF}_{4}\right]$ thin films to water vapor in the sealed ATR cell at different levels of $\mathrm{RH}$ at $295 \mathrm{~K}$. After each $\mathrm{RH}$ adjustment, spectra were collected until the band intensities stopped changing to ensure that equilibrium was attained. It typically took $\sim 20 \mathrm{~min}$ for the system to equilibrate. The spectra of the corresponding dry IL films were subtracted to emphasize changes induced by the uptake of water vapor. Note that this subtraction does not fully eliminate the bands attributable to IL vibrations because the refractive index of the film changes upon water uptake, thus affecting the penetration depth of the evanescent wave. The stronger bands that grow in the spectra are due to water
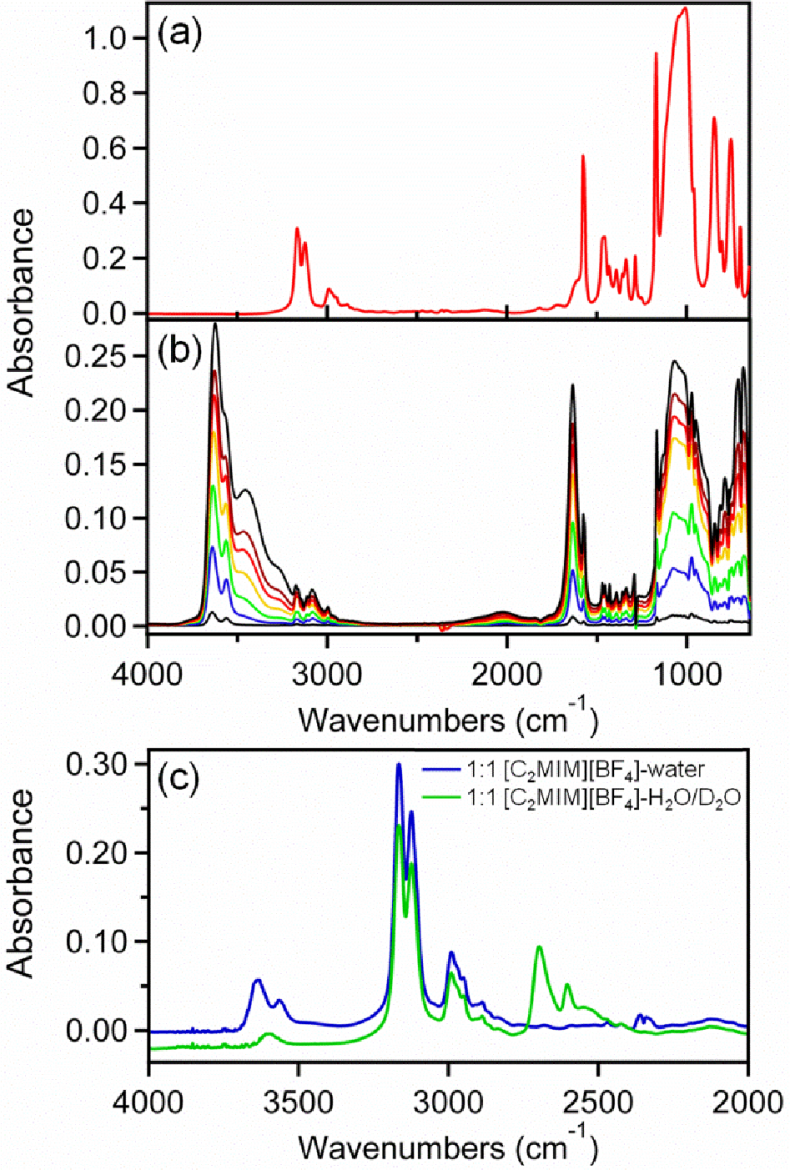

Figure 5. (a) ATR-FTIR spectra of dry $\left[\mathrm{C}_{2} \mathrm{MIM}\right]\left[\mathrm{BF}_{4}\right]$ on $\mathrm{ZnSe}$. (b) ATR-FTIR spectra of $\left[\mathrm{C}_{2} \mathrm{MIM}\right]\left[\mathrm{BF}_{4}\right]$ after exposure to increasing $\mathrm{RH}$ values of $3,22,41,61,71,78$, and $89 \%$ (the background contribution from the dry $\left[\mathrm{C}_{2} \mathrm{MIM}\right]\left[\mathrm{BF}_{4}\right]$ was subtracted). (c) ATR-FTIR spectra of $1: 1\left[\mathrm{C}_{2} \mathrm{MIM}\right]\left[\mathrm{BF}_{4}\right]$-water and 1:1 $\left[\mathrm{C}_{2} \mathrm{MIM}\right]\left[\mathrm{BF}_{4}\right]-\mathrm{H}_{2} \mathrm{O} / \mathrm{D}_{2} \mathrm{O}$ mixtures on $\mathrm{ZnSe}$.

vibrations. The growth of weaker bands is from an increase in the effective amount of material probed by the IR beam.

For $\left[\mathrm{C}_{2} \mathrm{MIM}\right][\mathrm{Cl}]$, uptake of water vapor produces a broad $\mathrm{O}-\mathrm{H}$ peak centered at $3378 \mathrm{~cm}^{-1}$ (Figure $4 \mathrm{~b}$ ). Other prominent feature from water are recognized as the bending band at 1637 $\mathrm{cm}^{-1}$ and a broad band at $\sim 2109 \mathrm{~cm}^{-1}$ assigned to a combination of the bending mode and a far-IR band associated with a librational motion of sterically hindered water molecules (Figure 4b).$^{82}$ As illustrated in Figure $4 \mathrm{~b}$, the intensity of these bands increases concomitantly with the increase in $\mathrm{RH}$ from the added water vapor. The slightly red-shifted $\left[\mathrm{C}_{2} \mathrm{MIM}^{+}\right]$ring bands (at 1568 and $1167 \mathrm{~cm}^{-1}$ ) and blue-shifted aromatic $\mathrm{C}-\mathrm{H}$ stretching bands also increase with $\mathrm{RH}$, though this increase is likely due to the change in the IR beam penetration depth mentioned above.

Compared to $\left[\mathrm{C}_{2} \mathrm{MIM}\right][\mathrm{Cl}]$ (Figure $4 \mathrm{~b}$ ), the interaction of water vapor with $\left[\mathrm{C}_{2} \mathrm{MIM}\right]\left[\mathrm{BF}_{4}\right]$ (Figure $5 \mathrm{~b}$ ) leads to very different IR spectra in the $\mathrm{O}-\mathrm{H}$ stretching region. At low $\mathrm{RH}$, there are two well-resolved bands, which can be assigned as the $\nu_{3}$ asymmetric stretch at $3640 \mathrm{~cm}^{-1}$ and the $\nu_{1}$ symmetric stretch at $3562 \mathrm{~cm}^{-1}$ of a water molecule that is $\mathrm{H}$-bonded to two $\left[\mathrm{BF}_{4}^{-}\right]$ anions, as suggested previously. ${ }^{19,27,30,81,83}$ As the $\mathrm{RH}$ is increased to $\sim 90 \% \mathrm{RH}$, the intensities of the $\nu_{3}$ and $\nu_{1} \mathrm{O}-\mathrm{H}$ stretches increase and the positions shift to $\sim 3625$ and $\sim 3568$ $\mathrm{cm}^{-1}$, respectively. A "liquid-like" water peak at $3454 \mathrm{~cm}^{-1}$ and a shoulder at $3270 \mathrm{~cm}^{-1}$ also appear and grow, indicative of 
formation of water aggregates. At higher RHs, there is also an increase in the ring bands associated with the $\left[\mathrm{C}_{2} \mathrm{MIM}^{+}\right]$cation (at 1576 and $1171 \mathrm{~cm}^{-1}$ ).

The $\mathrm{O}-\mathrm{H}$ stretching region is sensitive to $\mathrm{H}$-bonding and can offer insight into structural information on IL-water interactions. However, a strong coupling between the $\nu_{3}$ asymmetric stretch and $\nu_{1}$ symmetric stretches in water complicates interpretation of the spectrum and makes comparison with results from $\mathrm{MD}$ simulations difficult. To produce spectra that were free of such coupling effects, ATR-FTIR spectra of ILs mixed with either pure water or a mixture of ultrapure water in excess $\mathrm{D}_{2} \mathrm{O}\left(\mathrm{H}_{2} \mathrm{O} / \mathrm{D}_{2} \mathrm{O}\right)$, consisting primarily of $\mathrm{D}_{2} \mathrm{O}$ and $\mathrm{HOD}$ molecules, were compared. The IR spectra of $1: 1$ water and $\mathrm{H}_{2} \mathrm{O} / \mathrm{D}_{2} \mathrm{O}$ solutions of $\left[\mathrm{C}_{2} \mathrm{MIM}\right][\mathrm{Cl}]$ and $\left[\mathrm{C}_{2} \mathrm{MIM}\right]\left[\mathrm{BF}_{4}\right]$ are shown in Figures $4 \mathrm{c}$ and $5 \mathrm{c}$, respectively. We note that for the solution of $\left[\mathrm{C}_{2} \mathrm{MIM}\right][\mathrm{Cl}]$ in water the most prominent peak is a broad $\mathrm{O}-\mathrm{H}$ stretch at $\sim 3380 \mathrm{~cm}^{-1}$, identical to the band observed in the IL film exposed to water vapor (Figure $4 \mathrm{~b}$ ). Therefore, intentional mixing of $\left[\mathrm{C}_{2} \mathrm{MIM}\right][\mathrm{Cl}]$ and water produces the same type of $\mathrm{IL}-$ water solution as $\left[\mathrm{C}_{2} \mathrm{MIM}\right][\mathrm{Cl}]$ absorbing water vapor from ambient air.

For the $\left[\mathrm{C}_{2} \mathrm{MIM}\right][\mathrm{Cl}]-\mathrm{H}_{2} \mathrm{O} / \mathrm{D}_{2} \mathrm{O}$ mixture, the $\mathrm{O}-\mathrm{D}$ stretches of HOD and $\mathrm{D}_{2} \mathrm{O}$ appear around $2517 \mathrm{~cm}^{-1}$. The weaker band at $\sim 3400 \mathrm{~cm}^{-1}$ corresponds to the decoupled $\mathrm{O}-\mathrm{H}$ stretch in the $\left[\mathrm{C}_{2} \mathrm{MIM}\right][\mathrm{Cl}]-\mathrm{H}_{2} \mathrm{O} / \mathrm{D}_{2} \mathrm{O}$ mixture. The significant red-shift relative to gas-phase $\mathrm{HOD}\left(3707 \mathrm{~cm}^{-1}\right)$ and the width of this band are consistent with a strong $\mathrm{H}$-bonding interaction, most likely with the $\left[\mathrm{Cl}^{-}\right]$anion (although interaction with other water molecules cannot be ruled out based on the spectrum). In free $\mathrm{HOD}-\left[\mathrm{Cl}^{-}\right]$complexes, the $\mathrm{O}-\mathrm{H}$ stretch is even more redshifted relative to gas-phase HOD (down to $3156 \mathrm{~cm}^{-1}$ ). ${ }^{84}$ The smaller red-shift observed in the IL suggests that the strength of the interaction between water and $\left[\mathrm{Cl}^{-}\right]$is subdued (Figure $4 \mathrm{c}$ ).

In the case of the $\left[\mathrm{C}_{2} \mathrm{MIM}\right]\left[\mathrm{BF}_{4}\right]$-water solution, there are two discernible $\mathrm{O}-\mathrm{H}$ stretches seen in Figure $5 \mathrm{c}$, attributed to the $\nu_{3}$ asymmetric band at $\sim 3640 \mathrm{~cm}^{-1}$ and $\nu_{1}$ symmetric band at $\sim 3561 \mathrm{~cm}^{-1}$. The bands are identical in appearance to the corresponding bands in the IL film exposed to water vapor. In the $\left[\mathrm{C}_{2} \mathrm{MIM}\right]\left[\mathrm{BF}_{4}\right]-\mathrm{H}_{2} \mathrm{O} / \mathrm{D}_{2} \mathrm{O}$ mixture, the decoupled $\mathrm{O}-\mathrm{H}$ stretch from HOD appears at $3601 \mathrm{~cm}^{-1}$ and the $\nu_{3}$ and $\nu_{1}$ bands of the $\mathrm{D}_{2} \mathrm{O}$ molecules shift to $\sim 2699$ and $\sim 2605 \mathrm{~cm}^{-1}$, respectively. The narrow width and relatively high vibrational frequency of the decoupled $\mathrm{O}-\mathrm{H}$ stretch confirm the previous suggestion ${ }^{19,81}$ that water molecules in $\left[\mathrm{C}_{2} \mathrm{MIM}\right]\left[\mathrm{BF}_{4}\right]$ tend to be isolated from each other and interact primarily with the IL components.

The presence of water indirectly affects the $\mathrm{C}-\mathrm{H}$ stretching modes in the cation, and this effect is seen in Figures $4 \mathrm{c}$ and $5 \mathrm{c}$. The $\mathrm{C}-\mathrm{H}$ stretching bands in $\left[\mathrm{C}_{2} \mathrm{MIM}\right][\mathrm{Cl}]$ (Figure $4 \mathrm{c}$ ) are blue-shifted from the corresponding bands in the dry IL (Figure 4a). This blue-shift reflects weakened interactions between $\left[\mathrm{Cl}^{-}\right]$ and the cation. This effect is much smaller in $\left[\mathrm{C}_{2} \mathrm{MIM}\right]\left[\mathrm{BF}_{4}\right]$ : the aromatic $\mathrm{C}-\mathrm{H}$ stretching bands at $\sim 3166$ and $\sim 3123 \mathrm{~cm}^{-1}$ for both the water and $\mathrm{H}_{2} \mathrm{O} / \mathrm{D}_{2} \mathrm{O}$ solutions (Figure 5c) are essentially not shifted from the dry IL (Figure 5a).

Equilibrium Molar Fraction of Water in ILs. One of the key advantages of the TDMA measurements is that one can calculate $\chi_{\mathrm{w}}$ in the humidified particles exactly if the shapes and densities of the particles are known. Assuming that the nanoparticles are homogeneous spheres and that their densities are not substantially different from the densities of the corresponding bulk IL-water mixtures, one can derive the following relationship between GF and $\chi_{\mathrm{w}}$ (eq 2):

$$
\frac{\chi_{\mathrm{w}}}{1-\chi_{\mathrm{w}}}=\left(\frac{\mathrm{MW}_{\mathrm{IL}}}{\mathrm{MW}_{\mathrm{w}}}\right)\left(\frac{\rho_{\text {solution }}\left(\chi_{\mathrm{w}}\right)}{\rho_{\mathrm{IL}}} \mathrm{GF}^{3}-1\right)
$$

In this equation, MW is molecular weight, $\rho$ is density, and the subscripts IL, w, and solution refer to IL, water, and their mixture, respectively. The $\rho_{\text {solution }}$ data for $\left[\mathrm{C}_{2} \mathrm{MIM}\right]\left[\mathrm{BF}_{4}\right]$ from Rilo et al. ${ }^{85}$ were fitted to an empirical dependence on $\chi_{\mathrm{w}}$, and eq 2 was solved numerically for $\chi_{\mathrm{w}}$ for every measured GF. For example, $\chi_{\mathrm{w}}$ of $\left[\mathrm{C}_{2} \mathrm{MIM}\right]\left[\mathrm{BF}_{4}\right]$ nanoparticles at $83 \% \mathrm{RH}$ was $0.725 \pm 0.004$. Literature data for the physical properties of imidazolium-based ILs containing $\left[\mathrm{Cl}^{-}\right]$are scarce, so a formula based on an ideal solution behavior (i.e., additive volumes) was also derived (eq 3):

$$
\frac{\chi_{\mathrm{w}, \text { ideal }}}{1-\chi_{\mathrm{w}, \text { ideal }}}=\left(\frac{\mathrm{MW}_{\mathrm{IL}}}{\mathrm{MW}_{\mathrm{w}}}\right)\left(\frac{\rho_{\mathrm{w}}}{\rho_{\mathrm{IL}}}\right)\left(\mathrm{GF}^{3}-1\right)
$$

For $\left[\mathrm{C}_{2} \mathrm{MIM}\right]\left[\mathrm{BF}_{4}\right]$, both eqs 2 and 3 could be used to calculated $\chi$, whereas for $\left[\mathrm{C}_{2} \mathrm{MIM}\right][\mathrm{Cl}]$ particles only $\chi_{\text {w,ideal }}$ could be calculated due to the lack of density data for $\left[\mathrm{C}_{2} \mathrm{MIM}\right][\mathrm{Cl}]-$ water solutions. We believe eq 3 is a reasonable alternative to the more accurate eq 2 because it produces almost the same result, $\chi_{\text {w,ideal }}=0.739 \pm 0.004$ for $\left[\mathrm{C}_{2} \mathrm{MIM}\right]\left[\mathrm{BF}_{4}\right]$ at $83 \% \mathrm{RH}$. For $\left[\mathrm{C}_{2} \mathrm{MIM}\right][\mathrm{Cl}]$ nanoparticles, $\chi_{\mathrm{w}, \text { ideal }}$ was found to be $0.889 \pm$ 0.004 at $83 \% \mathrm{RH}$.

Strictly speaking, the equilibrium value of $\chi_{\mathrm{w}}$ in a bulk liquid and in a small droplet exposed to the same $\mathrm{RH}$ will not be the same because of the Kelvin effect (reduction in the equilibrium vapor pressure of a volatile solute above a curved surface). The Kelvin effect makes the hygroscopic GF of nanoparticles size dependent as demonstrated in previous work on hygroscopic growth of $\mathrm{NaCl}$ nanoparticles. ${ }^{68}$ However, for particles larger than $20 \mathrm{~nm}$, this effect is relatively small and quantitatively predictable from bulk thermodynamics properties. ${ }^{86,87}$ The Kelvin correction factor for the IL nanoparticles was estimated using surface tension versus water content measurements from Rilo et al. ${ }^{85}$ For the $\sim 27 \mathrm{~nm}$ nanoparticles, the anticipated reduction in $\chi_{\mathrm{w}}$ compared to bulk is less than $5 \%$ for $\left[\mathrm{C}_{2} \mathrm{MIM}\right]\left[\mathrm{BF}_{4}\right]$. The Kelvin effect correction could not be calculated for $\left[\mathrm{C}_{2} \mathrm{MIM}\right][\mathrm{Cl}]$ due to lack of available surface tension data for the $\left[\mathrm{C}_{2} \mathrm{MIM}\right][\mathrm{Cl}]$-water mixtures, but we believe it to be similarly small. In view of the small size of the Kelvin effect corrections, the reported $\chi_{\mathrm{w}}$ values were not corrected for this effect.

Figure 6a shows the dependence of the $\chi_{\mathrm{w}}$ in the ILs as a function of the $\mathrm{RH}$, obtained by a direct inversion of the growth curves using eqs 2 and 3 . With the exception of the small Kelvin effect correction and the uncertainty introduced by the unknown density of the $\left[\mathrm{C}_{2} \mathrm{MIM}\right][\mathrm{Cl}]$-water mixtures, the accuracy of the $\chi_{\mathrm{w}}$ values should be comparable to that of bulk measurements. $\mathrm{RH}$ is intentionally placed on the vertical axis to discuss this dependence in terms of Raoult's law (RH can be interpreted as the equilibrium vapor pressure of water above the $\mathrm{IL}-$ water mixture). The behaviors of $\left[\mathrm{C}_{2} \mathrm{MIM}\right][\mathrm{Cl}]$ and $\left[\mathrm{C}_{2} \mathrm{MIM}\right]\left[\mathrm{BF}_{4}\right]$ are distinctly different. $\left[\mathrm{C}_{2} \mathrm{MIM}\right]\left[\mathrm{BF}_{4}\right]$ exhibits relatively small positive deviations from Raoult's law. This suggests that the strength of $\left[\mathrm{C}_{2} \mathrm{MIM}\right]\left[\mathrm{BF}_{4}\right]$-water interactions is weaker than or comparable in strength to the interactions of water-water and IL-IL. This is consistent with the narrow widths and small redshifts of the $\mathrm{O}-\mathrm{H}$ stretching bands in ATR-FTIR spectra of $\left[\mathrm{C}_{2} \mathrm{MIM}\right]\left[\mathrm{BF}_{4}\right]$ (Figure 5), which show that water molecules are not significantly perturbed by interactions with $\left[\mathrm{C}_{2} \mathrm{MIM}\right]\left[\mathrm{BF}_{4}\right]$, and conversely, they do not significantly affect vibrations of the 


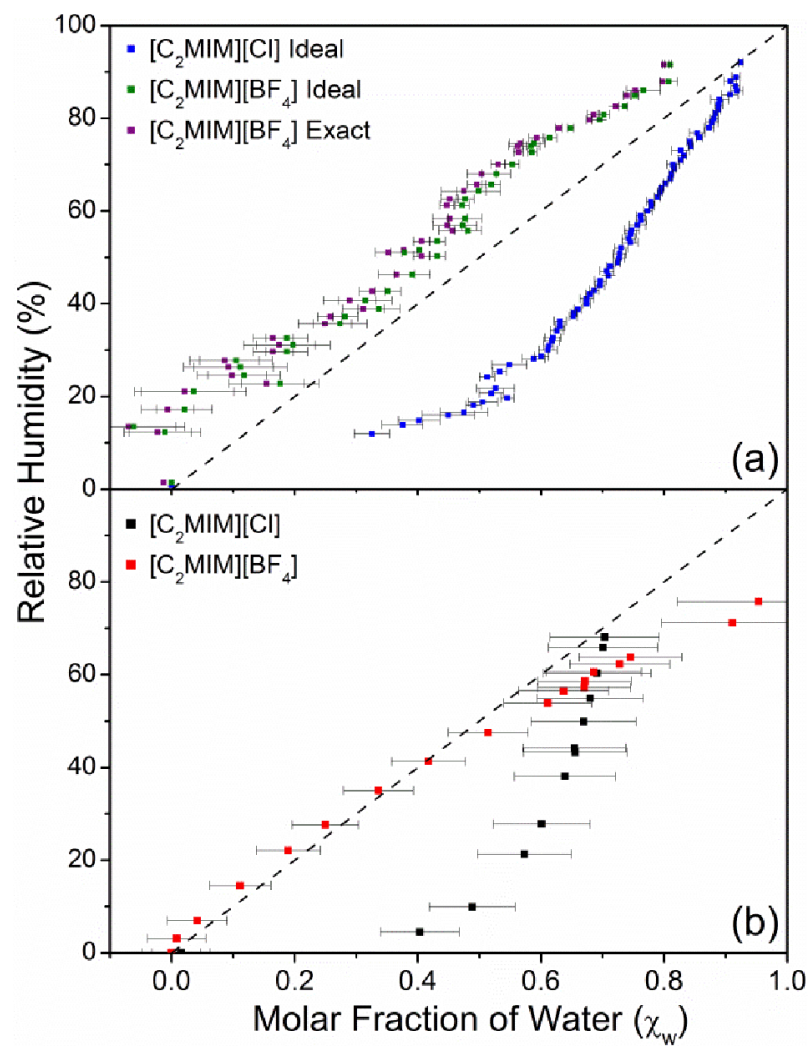

Figure 6. Molar fractions of water $\left(\chi_{\mathrm{w}}\right)$ as a function of RH: (a) calculated from the GF values using eq 2 (actual densities) and eq 3 (ideal solution approximation); (b) inferred from the ATR-FTIR spectra. The dashed line on both plots represents Raoult's law in terms of an ideal solution.

cation and the anion. In contrast to $\left[\mathrm{C}_{2} \mathrm{MIM}\right]\left[\mathrm{BF}_{4}\right],\left[\mathrm{C}_{2} \mathrm{MIM}\right]$ $[\mathrm{Cl}]$-water mixtures exhibit significant negative deviation in terms of Raoult's law as a result of the very strong interactions between water and $\left[\mathrm{Cl}^{-}\right]$. This is again consistent with the IR spectra of the aqueous $\left[\mathrm{C}_{2} \mathrm{MIM}\right][\mathrm{Cl}]$ solutions (Figure 4 ), which display a strongly red-shifted and broad $\mathrm{O}-\mathrm{H}$ stretching band.

From the ATR-FTIR measurements, $\chi_{\mathrm{w}}$ in the IL film exposed to water vapor can be estimated by comparing the relative areas of the $\mathrm{C}-\mathrm{H}$ and $\mathrm{O}-\mathrm{H}$ stretching vibrations. We calibrated this method by recording the ATR-FTIR spectra of premixed aqueous solutions of ILs of known composition. This method is necessarily approximate because the presence of water may affect the band strengths of the $\mathrm{C}-\mathrm{H}$ vibrations, and vice versa, the $\mathrm{O}-\mathrm{H}$ stretch band strengths may be influenced by the IL components to a different extent depending on the extent of dilution. Furthermore, it is difficult to cleanly separate the overlapping $\mathrm{C}-\mathrm{H}$ and $\mathrm{O}-\mathrm{H}$ stretches from each other because of the RH-dependent shifts in the positions of the bands. Nevertheless, the RH vs $\chi_{\mathrm{w}}$ curves obtained from the ATR-FTIR measurements (Figure $6 \mathrm{~b}$ ) are in good qualitative agreement with the nanoparticle hygroscopicity data. The data shown in both panels of Figure 6 complement each other: the ATR-FTIR results are most accurate at low $\mathrm{RH}$, whereas the nanoparticle hygroscopicity results are most accurate at higher $\mathrm{RH}$ values (excluding values $>85 \% \mathrm{RH}$ due to the high sensitivity of $\mathrm{RH}$ to temperature).

MD Simulations of 1:1 IL-Water Mixtures. MD simulations of $\left[\mathrm{C}_{2} \mathrm{MIM}\right][\mathrm{Cl}]$ and $\left[\mathrm{C}_{2} \mathrm{MIM}\right]\left[\mathrm{BF}_{4}\right]$ mixed with water in 1:1 molar ratios were carried out to elucidate the interactions of water with the IL components and help interpret the observed FTIR spectra. Figure 7 and Table 1 compare
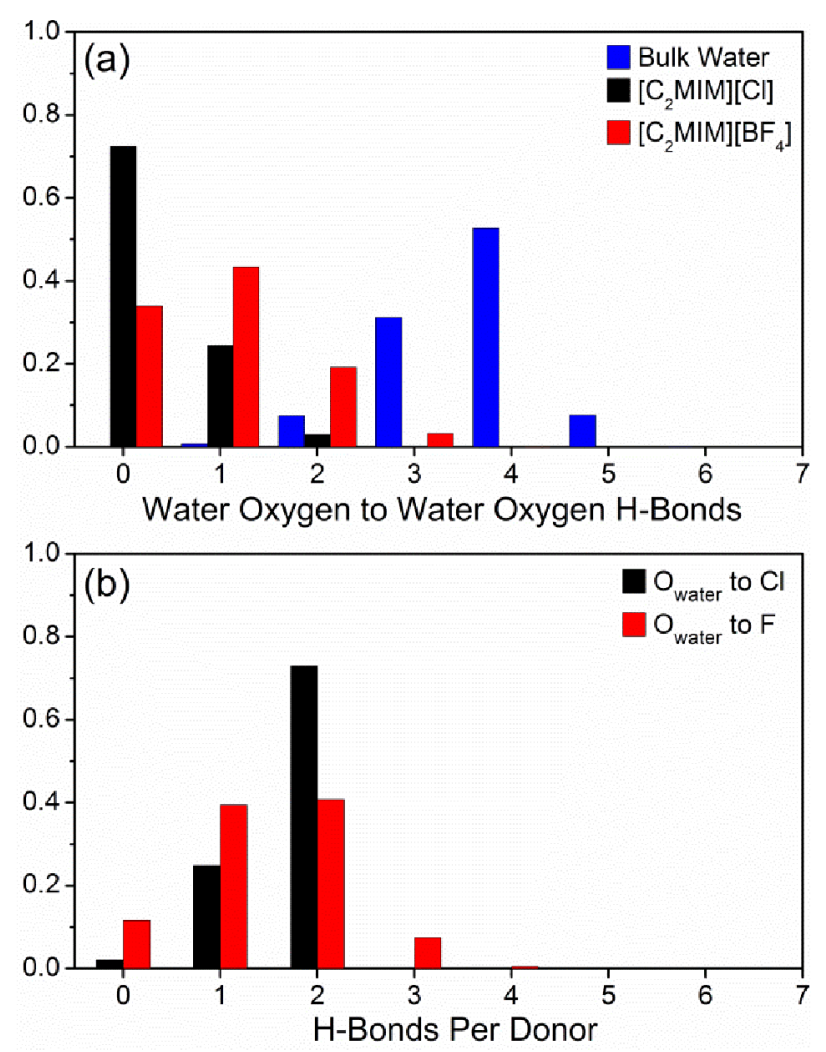

Figure 7. Hydrogen bond (H-bond) distribution histograms from MD simulation trajectories of $(\mathrm{a})$ water oxygen $\left(\mathrm{O}_{\text {water }}\right)$ to $\mathrm{O}_{\text {water }} \mathrm{H}$-bonds in 1:1 mixtures of water with either bulk water, $\left[\mathrm{C}_{2} \mathrm{MIM}\right][\mathrm{Cl}]$, or $\left[\mathrm{C}_{2} \mathrm{MIM}\right]\left[\mathrm{BF}_{4}\right]$ and (b) $\mathrm{O}_{\text {water }}$ donor H-bonds to either chloride or fluorine anions.

Table 1. Water Solvation Predicted by MD Simulations ${ }^{a}$

\begin{tabular}{|cccc}
\hline water-water & first shell $(\AA)$ & c.n. & H-bonds \\
bulk water & 3.35 & 4.7 & 3.6 \\
{$\left[\mathrm{C}_{2} \mathrm{MIM}\right][\mathrm{Cl}]$} & 3.25 & 0.36 & 0.3 \\
{$\left[\mathrm{C}_{2} \mathrm{MIM}\right]\left[\mathrm{BF}_{4}\right]$} & 3.65 & 1.15 & 0.9 \\
water-anion & first shell $(\AA)$ & c.n. & H-bonds \\
$\mathrm{O}_{\text {water }}$ to $\mathrm{Cl}$ & 4.05 & 1.85 & 1.7 \\
$\mathrm{O}_{\text {water }}$ to $\mathrm{F}$ & 3.55 & 0.55 & 1.5 \\
$\mathrm{O}_{\text {water }}$ to B & 4.65 & 1.61 & 0
\end{tabular}

${ }^{a}$ First coordination shell location, coordination number (c.n.), and average number of hydrogen bonds (H-bonds) for water-water and water-anion interactions in 1:1 mixtures of water with either bulk water, $\left[\mathrm{C}_{2} \mathrm{MIM}\right][\mathrm{Cl}]$, or $\left[\mathrm{C}_{2} \mathrm{MIM}\right]\left[\mathrm{BF}_{4}\right]$.

water-water and water-anion H-bond distributions in the ILs with those in bulk water. Water-water H-bonding interactions are mostly abolished in $\left[\mathrm{C}_{2} \mathrm{MIM}\right][\mathrm{Cl}]$ and replaced by wateranion interactions. In contrast, both water-water and wateranion interactions coexist in $\left[\mathrm{C}_{2} \mathrm{MIM}\right]\left[\mathrm{BF}_{4}\right]$. Thus, the $\mathrm{MD}$ simulations are consistent with the IR spectra of water in ILs, which revealed strong interactions between water and the anion in $\left[\mathrm{C}_{2} \mathrm{MIM}\right][\mathrm{Cl}]$, and coexistence of both water-anion and water-water interactions in $\left[\mathrm{C}_{2} \mathrm{MIM}\right]\left[\mathrm{BF}_{4}\right]$. Representative snapshots depicting the distribution of water in the ILs and interactions of water with the IL components are shown in Figure 8. 


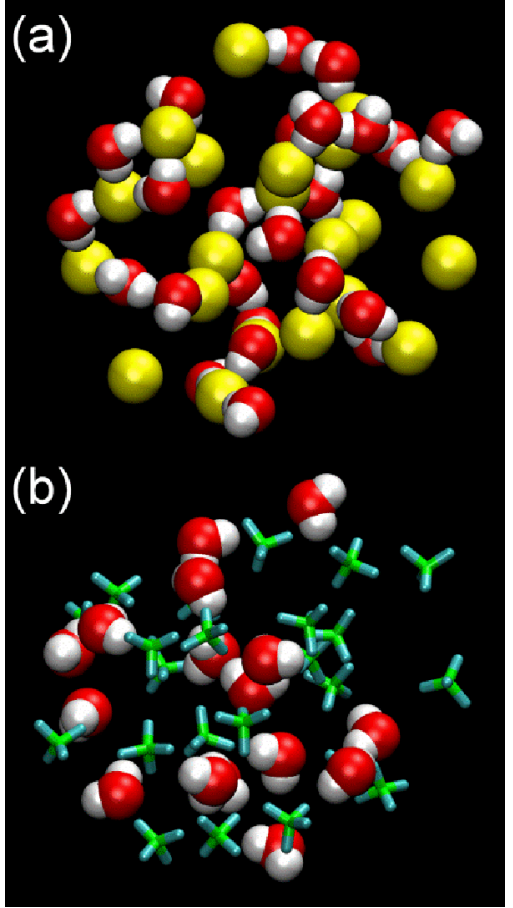

Figure 8. Representative $\mathrm{MD}$ simulation snapshots of $\left[\mathrm{C}_{2} \mathrm{MIM}\right][\mathrm{Cl}]$ (a) and $\left[\mathrm{C}_{2} \mathrm{MIM}\right]\left[\mathrm{BF}_{4}\right]$ (b) mixed with water in 1:1 molar ratios. Water molecule are shown as filled spheres and colored by atom (red: oxygen; white: hydrogen). $\left[\mathrm{Cl}^{-}\right]$ions are shown as yellow, filled spheres. $\left[\mathrm{BF}_{4}^{-}\right]$ ions are represented as licorice and colored by atom (green: boron; cyan: fluoride). Cation molecules were removed for clarity.

To identify H-bond configurations in the mixed systems, a geometric criterion commonly used for bulk water was applied (donor-acceptor distance $<3.5 \AA$ and donor-H-acceptor angle $>140^{\circ}$ ). The water oxygen radial distribution function (Figure 9a) yields similar locations for the first coordination shell and a similar trend in coordination number as the $\mathrm{H}$-bond distributions mean values (Table 1), suggesting that this geometric criterion adequately describes $\mathrm{H}$-bond interactions in the mixed system. Figure $9 \mathrm{~b}$ shows the water oxygen to anion $\left(\mathrm{O}_{\text {water }}\right.$-anion $)$ radial distribution functions for the 1:1 IL-water mixtures. Because of the smaller size of the fluorine atom, the average $\mathrm{O}_{\text {water }}-\mathrm{F}$ separation in $\left[\mathrm{C}_{2} \mathrm{MIM}\right]\left[\mathrm{BF}_{4}\right]$ is significantly smaller than the $\mathrm{O}_{\text {water }}-\mathrm{Cl}$ separation in $\left[\mathrm{C}_{2} \mathrm{MIM}\right][\mathrm{Cl}]$. However, the interaction strength is larger in the latter because the negative charge in $\left[\mathrm{BF}_{4}^{-}\right]$is more spatially distributed. The ionic complex $\mathrm{Cl}^{-} \cdots \mathrm{H}_{2} \mathrm{O}$ has been investigated in the gas phase by a number of experimental and theoretical methods; ${ }^{88}$ its binding energy is $59 \mathrm{~kJ} \mathrm{~mol}^{-1}$. In contrast, no experiments or calculations have been performed on the $\mathrm{BF}_{4}{ }^{-} \cdots \mathrm{H}_{2} \mathrm{O}$ complex to the best of our knowledge. It would be of interest to investigate the nature of $\mathrm{H}$ bonding in this complex in the future.

We also predicted the frequency distributions corresponding to the $\mathrm{O}-\mathrm{H}$ stretching vibration of water in $\left[\mathrm{C}_{2} \mathrm{MIM}\right][\mathrm{Cl}]$, $\left[\mathrm{C}_{2} \mathrm{MIM}\right]\left[\mathrm{BF}_{4}\right]$, and bulk water from the $\mathrm{MD}$ simulations, using an empirical relation between the electric field along the $\mathrm{O}-\mathrm{H}$ bond and the $\mathrm{O}-\mathrm{H}$ vibrational frequency derived for the SPC/E water model by Smith et al. ${ }^{63}$ Figure 10 compares these results with the ATR-FTIR data for the $\mathrm{O}-\mathrm{H}$ stretch of HOD molecules in $\left[\mathrm{C}_{2} \mathrm{MIM}\right][\mathrm{Cl}],\left[\mathrm{C}_{2} \mathrm{MIM}\right]\left[\mathrm{BF}_{4}\right]$, and bulk water. The simulations qualitatively reproduce the experimental observations. Specifically, the red-shift in the $\mathrm{O}-\mathrm{H}$ stretch is predicted to be smaller in $\left[\mathrm{C}_{2} \mathrm{MIM}\right]\left[\mathrm{BF}_{4}\right]$ compared to $\left[\mathrm{C}_{2} \mathrm{MIM}\right][\mathrm{Cl}]$, the

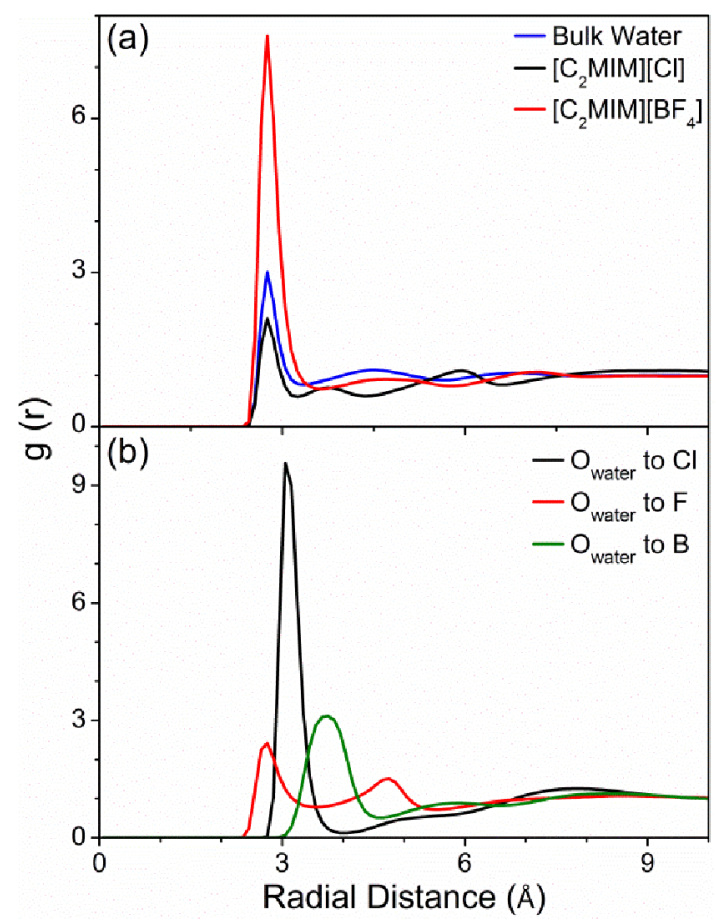

Figure 9. Radial distribution functions from MD simulations of (a) water oxygen $\left(\mathrm{O}_{\text {water }}\right)$ to $\mathrm{O}_{\text {water }}$ in 1:1 mixtures of water with either bulk water, $\left[\mathrm{C}_{2} \mathrm{MIM}\right][\mathrm{Cl}]$, or $\left[\mathrm{C}_{2} \mathrm{MIM}\right]\left[\mathrm{BF}_{4}\right]$ and $(\mathrm{b}) \mathrm{O}_{\text {water }}$ around $\mathrm{IL}$ anions. Separate radial distribution functions for fluorine and boron were calculated for $\left[\mathrm{C}_{2} \mathrm{MIM}\right]\left[\mathrm{BF}_{4}\right]$.

red-shift in $\left[\mathrm{C}_{2} \mathrm{MIM}\right][\mathrm{Cl}]$ approaches that in bulk water, and the width of the bands is the largest in bulk water. This level of agreement gives us confidence that the force fields chosen for the MD simulations correctly capture the essential interactions in the IL-water mixtures and validates the differences in ion-water and water-water interactions in $\left[\mathrm{C}_{2} \mathrm{MIM}\right]\left[\mathrm{BF}_{4}\right]$ vs $\left[\mathrm{C}_{2} \mathrm{MIM}\right]$ $[\mathrm{Cl}]$ predicted by the $\mathrm{MD}$ simulations.

\section{CONCLUSION}

In this study, we have combined aerosol hygroscopicity methods, IR spectroscopy, and MD simulations to gain new insights into the interaction of water vapor with IL nanoparticles and thin films. Although the ILs under investigation, $\left[\mathrm{C}_{2} \mathrm{MIM}\right][\mathrm{Cl}]$ and $\left[\mathrm{C}_{2} \mathrm{MIM}\right]\left[\mathrm{BF}_{4}\right]$, share the same cation and only differ in the inorganic anion, their interaction with water is remarkably different. First, $\left[\mathrm{C}_{2} \mathrm{MIM}\right][\mathrm{Cl}]$ takes up more water under equilibrium conditions than $\left[\mathrm{C}_{2} \mathrm{MIM}\right]\left[\mathrm{BF}_{4}\right]$ at all $\mathrm{RH}$ values. This is evident from the larger hygroscopic GFs for the $\left[\mathrm{C}_{2} \mathrm{MIM}\right][\mathrm{Cl}]$ nanoparticles and stronger water IR absorption bands for the $\left[\mathrm{C}_{2} \mathrm{MIM}\right][\mathrm{Cl}]$ thin films exposed to water vapor. Second, the equilibrium vapor pressure above $\left[\mathrm{C}_{2} \mathrm{MIM}\right][\mathrm{Cl}]$ exhibits negative deviation from Raoult's law, whereas $\left[\mathrm{C}_{2} \mathrm{MIM}\right]$ $\left[\mathrm{BF}_{4}\right]$ deviates from Raoult's law in a positive sense. Third, the shapes of the $\mathrm{O}-\mathrm{H}$ stretching bands for water molecules absorbed into ILs are quite different. At low $\chi_{\mathrm{w}}$, the $\nu_{3}$ and $\nu_{1}$ bands in $\left[\mathrm{C}_{2} \mathrm{MIM}\right]\left[\mathrm{BF}_{4}\right]$ are narrow, well resolved, and not significantly shifted from the $\mathrm{O}-\mathrm{H}$ stretches in free water. In contrast, for $\left[\mathrm{C}_{2} \mathrm{MIM}\right][\mathrm{Cl}]$, these bands coalesce into one broad $\mathrm{O}-\mathrm{H}$ stretching band characterized by a significant red-shift. At higher $\chi_{w}$, additional bands in $\left[\mathrm{C}_{2} \mathrm{MIM}\right]\left[\mathrm{BF}_{4}\right]$ appear in the $\mathrm{O}-$ $\mathrm{H}$ stretching region characteristic of water aggregates. Fourth, $\mathrm{MD}$ simulations predict that water is more strongly associated with the anions than itself, especially so in $\left[\mathrm{C}_{2} \mathrm{MIM}\right][\mathrm{Cl}]$. This is 


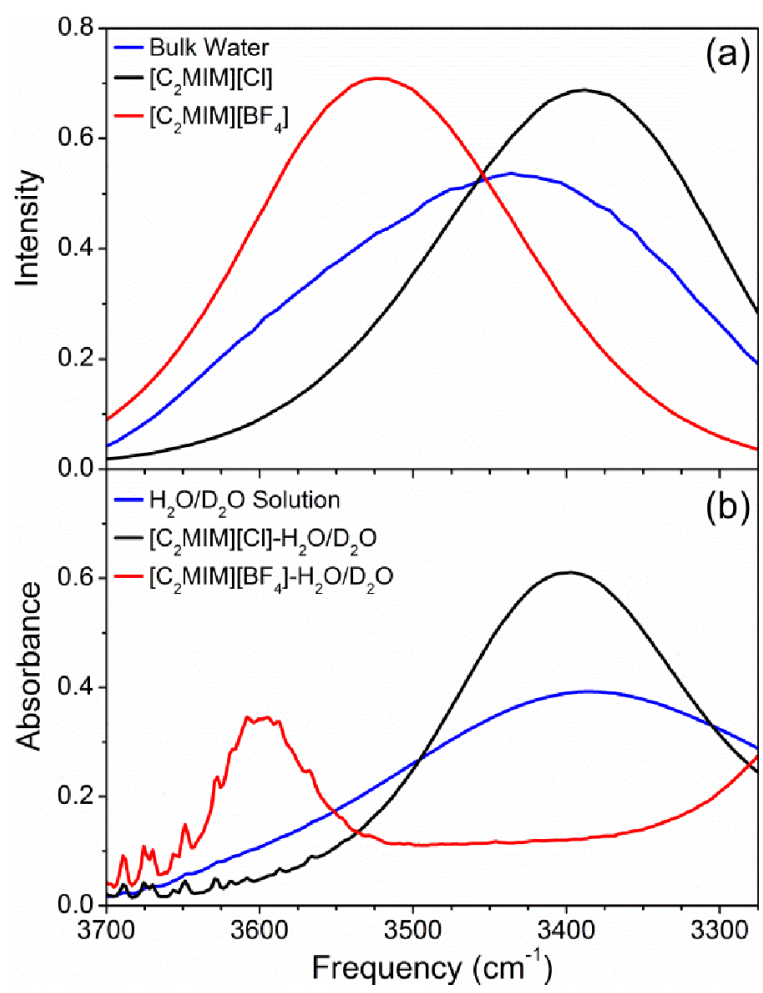

Figure 10. (a) Simulated frequency distributions corresponding to the $\mathrm{O}-\mathrm{H}$ stretching vibration of water in either bulk water, $\left[\mathrm{C}_{2} \mathrm{MIM}\right][\mathrm{Cl}]$, or $\left[\mathrm{C}_{2} \mathrm{MIM}\right]\left[\mathrm{BF}_{4}\right]$. (b) Shown for comparison are the experimental ATR-FTIR spectra of the decoupled $\mathrm{O}-\mathrm{H}$ stretches in a bulk solution of $\mathrm{H}_{2} \mathrm{O}$ in excess $\mathrm{D}_{2} \mathrm{O}\left(\mathrm{H}_{2} \mathrm{O} / \mathrm{D}_{2} \mathrm{O}\right)$ and in $\mathrm{ILs}-\mathrm{H}_{2} \mathrm{O} / \mathrm{D}_{2} \mathrm{O}$ mixtures. ATRFTIR spectra for the IL $-\mathrm{H}_{2} \mathrm{O} / \mathrm{D}_{2} \mathrm{O}$ mixtures were baseline corrected for easier comparison.

evident from low water-water and high water-anion coordination numbers.

The following picture emerges from this combination of the experimental observations and MD simulations. When ILs are exposed to low levels of $\mathrm{RH}$, absorbed water molecules are primarily interacting with the anion. This interaction is considerably stronger in the case of $\left[\mathrm{C}_{2} \mathrm{MIM}\right][\mathrm{Cl}]$, and this accounts for its large hygroscopic $\mathrm{GF}$, significant $\mathrm{O}-\mathrm{H}$ red-shift, and large deviations from Raoult's law. The behavior of the $\left[\mathrm{C}_{2} \mathrm{MIM}\right]\left[\mathrm{BF}_{4}\right]$-water mixture is much closer to that of an ideal solution because of more balanced interactions between the mixture components. At higher $\mathrm{RH}$, when enough water is absorbed by the ILs, the relative role of water-water interaction increases, and small clusters and chains of water molecules exist in the IL-water solution.

The amount of water that ILs can absorb under equilibrium conditions at any given $\mathrm{RH}$ is finite but quite substantial. For example, $\left[\mathrm{C}_{2} \mathrm{MIM}\right][\mathrm{Cl}]$ and $\left[\mathrm{C}_{2} \mathrm{MIM}\right]\left[\mathrm{BF}_{4}\right]$ forgotten on a shelf at $83 \% \mathrm{RH}$ will reach equilibrium $\chi_{\mathrm{w}}$ of $\sim 0.73$ and $\sim 0.89$, respectively. The equilibrium values of $\chi_{\mathrm{w}}$ attained at other $\mathrm{RH}$ values can be estimated from Figure 6 in this paper. The amount of time needed to reach this equilibrium will of course depend on the amount of IL. While it takes less than a second for nanoparticles (one of the chief advantages of the hygroscopic growth method described here), and less than $30 \mathrm{~min}$ for thin films of ILs, it will take considerably longer for bulk quantities, as previous studies cited in the Introduction suggest. Both the amount of water that can be absorbed from the air, and the time scale of this process, represent important practical knowledge about ILs considering the significant effect of absorbed water on various physicochemical properties of ILs, including density, surface tension, and the ability to dissolve other compounds.

\section{AUTHOR INFORMATION}

\section{Corresponding Author}

*E-mail nizkorod@uci.edu; Tel +1-949-824-1262.

\section{Notes}

The authors declare no competing financial interest.

\section{ACKNOWLEDGMENTS}

We gratefully acknowledge financial support from the National Science Foundation (CHE-0909227). A.C.M. is grateful to the National Science Foundation for a NSF graduate student fellowship. T.M.M. acknowledges support from the UCI School of Physical Sciences Center for Solar Energy. The authors give special thanks to Nathaniel Sickerman at UCI for helpful discussions, Dr. Andy Borovik's Group at UCI for use of their solvent line, Dr. Larry Overman's Group at UCI for use of their Karl Fischer titrator, and John Morrison for help with the initial setup for the MD simulations. T.M.M. thanks Ross Boyle, Thermo Fisher Scientific, for useful discussions.

\section{REFERENCES}

(1) Ionic Liquids in Synthesis, 2nd ed.; Wasserscheid, P., Welton, T., Eds.; Wiley-VCH: Weinheim, Germany, 2008; Vol. 1.

(2) Rogers, R. D.; Seddon, K. R. Science 2003, 302, 792-793.

(3) Seddon, K. R.; Stark, A.; Torres, M.-J. Pure Appl. Chem. 2000, 72, $2275-2287$.

(4) Ionic Liquids: Industrial Applications for Green Chemistry; Rogers, R. D., Seddon, K. R., Eds.; ACS Symposium Series 818; American Chemical Society: Washington, DC, 2002.

(5) Ionic Liquids as Green Solvents: Progress and Prospects; Rogers, R. D., Seddon, K. R., Eds.; ACS Symposium Series 856; American Chemical Society: Washington, DC, 2003.

(6) Welton, T. Chem. Rev. 1999, 99, 2071-2083.

(7) Electrochemical Aspects of Ionic Liquids; Ohno, H., Ed.; WileyInterscience: Hoboken, NJ, 2005.

(8) Ficke, L. E.; Brennecke, J. F. J. Phys. Chem. B 2010, 114, 1049610501.

(9) Masaki, T.; Nishikawa, K.; Shirota, H. J. Phys. Chem. B 2010, 114, 6323-6331.

(10) Sun, B.; Wu, P. J. Phys. Chem. B 2010, 114, 9209-9219.

(11) Singh, T.; Kumar, A. Vib. Spectrosc. 2011, 55, 119-125.

(12) Di Francesco, F.; Calisi, N.; Creatini, M.; Melai, B.; Salvo, P.; Chiappe, C. Green Chem. 2011, 13, 1712-1717.

(13) Maiti, A.; Rogers, R. D. Phys. Chem. Chem. Phys. 2011, 13, 1213812145 .

(14) Hou, J.; Zhang, Z.; Madsen, L. A. J. Phys. Chem. B 2011, 115, $4576-4582$.

(15) Dupont, J. J. Braz. Chem. Soc. 2004, 15, 341-350.

(16) Freire, M. G.; Santos, L.; Fernandes, A. M.; Coutinho, J. A. P.; Marrucho, I. M. Fluid Phase Equilib. 2007, 261, 449-454.

(17) Tran, C. D.; Lacerda, S. H. D.; Oliveira, D. Appl. Spectrosc. 2003, 57, $152-157$.

(18) Anthony, J. L.; Maginn, E. J.; Brennecke, J. F. J. Phys. Chem. B 2001, 105, 10942-10949.

(19) Cammarata, L.; Kazarian, S. G.; Salter, P. A.; Welton, T. Phys. Chem. Chem. Phys. 2001, 3, 5192-5200.

(20) Mele, A.; Tran, C. D.; Lacerda, S. H. D. Angew. Chem., Int. Ed. 2003, 42, 4364-4366.

(21) Saha, S.; Hamaguchi, H.-o. J. Phys. Chem. B 2006, 110, 27772781.

(22) Rodríguez, H.; Brennecke, J. F. J. Chem. Eng. Data 2006, 51, $2145-2155$ 
(23) Wang, Y.; Li, H.; Han, S. J. Phys. Chem. B 2006, 110, 2464624651 .

(24) Rollet, A.-L.; Porion, P.; Vaultier, M.; Billard, I.; Deschamps, M.; Bessada, C.; Jouvensal, L. J. Phys. Chem. B 2007, 111, 11888-11891.

(25) Jiang, W.; Wang, Y.; Voth, G. A. J. Phys. Chem. B 2007, 111, 48124818.

(26) Schroder, C.; Rudas, T.; Neumayr, G.; Benkner, S.; Steinhauser, O. J. Chem. Phys. 2007, 127, 234503.

(27) Fazio, B.; Triolo, A.; Di Marco, G. J. Raman Spectrosc. 2008, 39, 233-237.

(28) Moreno, M.; Castiglione, F.; Mele, A.; Pasqui, C.; Raos, G. J. Phys. Chem. B 2008, 112, 7826-7836.

(29) Hanke, C. G.; Atamas, N. A.; Lynden-Bell, R. M. Green Chem. 2002, 4, 107-111.

(30) Takamuku, T.; Kyoshoin, Y.; Shimomura, T.; Kittaka, S.; Yamaguchi, T. J. Phys. Chem. B 2009, 113, 10817-10824.

(31) Hanke, C. G.; Lynden-Bell, R. M. J. Phys. Chem. B 2003, 107, 10873-10878.

(32) Fumino, K.; Wulf, A.; Ludwig, R. Angew. Chem., Int. Ed. 2008, 47, $3830-3834$

(33) Gao, Y.; Zhang, L.; Wang, Y.; Li, H. J. Phys. Chem. B 2010, 114, $2828-2833$.

(34) Cuadrado-Prado, S.; Dominguez-Perez, M.; Rilo, E.; GarciaGarabal, S.; Segade, L.; Franjo, C.; Cabeza, O. Fluid Phase Equilib. 2009, 278, 36-40.

(35) Dang, L. X.; Wick, C. D. J. Phys. Chem. B 2011, 115, 6964-6970.

(36) Köddermann, T.; Wertz, C.; Heintz, A.; Ludwig, R. Angew. Chem., Int. Ed. 2006, 45, 3697-3702.

(37) Djikaev, Y. S.; Ruckenstein, E. J. Chem. Phys. 2006, 124, 194709.

(38) Huddleston, J. G.; Visser, A. E.; Reichert, W. M.; Willauer, H. D.; Broker, G. A.; Rogers, R. D. Green Chem. 2001, 3, 156-164.

(39) Gomez, E.; Gonzalez, B.; Dominguez, A.; Tojo, E.; Tojo, J. J. Chem. Eng. Data 2006, 51, 696-701.

(40) Ghatee, M. H.; Zolghadr, A. R. Fluid Phase Equilib. 2008, 263, 168-175.

(41) Alshawa, A.; Dopfer, O.; Harmon, C. W.; Nizkorodov, S. A.; Underwood, J. S. J. Phys. Chem. A 2009, 113, 7678-7686.

(42) Harmon, C. W.; Grimm, R. L.; McIntire, T. M.; Peterson, M. D.; Njegic, B.; Angel, V. M.; Alshawa, A.; Underwood, J. S.; Tobias, D. J.; Gerber, R. B.; Gordon, M. S.; Hemminger, J. C.; Nizkorodov, S. A. J. Phys. Chem. B 2010, 114, 2435-2449.

(43) Hogan, C. J.; de la Mora, J. F. J. Am. Soc. Mass Spectrom. 2010, 21, $1382-1386$.

(44) Hogan, C. J.; de la Mora, J. F. Phys. Chem. Chem. Phys. 2009, 11, $8079-8090$

(45) Ku, B. K.; de la Mora, J. F. Aerosol Sci. Technol. 2009, 43, 241-249.

(46) Larriba, C.; Hogan, C. J.; Attoui, M.; Borrajo, R.; Garcia, J. F.; de la

Mora, J. F. Aerosol Sci. Technol. 2011, 45, 453-467.

(47) Rader, D. J.; McMurry, P. H. J. Aerosol Sci. 1986, 17, 771-787.

(48) Smith, J. D.; Cappa, C. D.; Wilson, K. R.; Cohen, R. C.; Geissler, P. L.; Saykally, R. J. Proc. Natl. Acad. Sci. U. S. A. 2005, 102, 14171-14174.

(49) Tyler, J. M.; Branton, D. J. Ultrastruct. Res. 1980, 71, 95-102.

(50) McIntire, T. M.; Brant, D. A. Biopolymers 1997, 42, 133-146.

(51) Phillips, J. C.; Braun, R.; Wang, W.; Gumbart, J.; Tajkhorshid, E.; Villa, E.; Chipot, C.; Skeel, R. D.; Kale, L.; Schulten, K. J. Comput. Chem. 2005, 26, 1781-1802.

(52) de Andrade, J.; Boes, E. S.; Stassen, H. J. Phys. Chem. B 2002, 106, 13344-13351.

(53) Beglov, D.; Roux, B. J. Chem. Phys. 1996, 104, 8678-8689.

(54) Berendsen, H. J. C.; Grigera, J. R.; Straatsma, T. P. J. Phys. Chem.

1987, 91, 6269-6271.

(55) Darden, T.; York, D.; Pedersen, L. J. Chem. Phys. 1993, 98, 10089-10092.

(56) Essmann, U.; Perera, L.; Berkowitz, M. L.; Darden, T.; Lee, H.; Pedersen, L. G. J. Chem. Phys. 1995, 103, 8577-8593.

(57) Grubmüller, H.; Heller, H.; Windemuth, A.; Schulten, K. Mol. Simul. 1991, 6, 121-142.

(58) Ryckaert, J.-P.; Ciccotti, G.; Berendsen, H. J. C. J. Comput. Phys. 1977, 23, 327-341.
(59) Miyamoto, S.; Kollman, P. J. Comput. Chem. 1992, 13, 952-962. (60) Feller, S. E.; Zhang, Y.; Pastor, R. W.; Brooks, B. R. J. Chem. Phys. 1995, 103, 4613-4621.

(61) Martyna, G. J.; Tobias, D. J.; Klein, M. L. J. Chem. Phys. 1994, 101, 4177-4189.

(62) Humphrey, W.; Dalke, W.; Schulten, K. J. Mol. Graphics 1996, 14, $33-38$.

(63) Smith, J. D.; Saykally, R. J.; Geissler, P. L. J. Am. Chem. Soc. 2007, 129, 13847-13856.

(64) DeCarlo, P. F.; Slowik, J. G.; Worsnop, D. R.; Davidovits, P.; Jimenez, J. L. Aerosol Sci. Technol. 2004, 38, 1185-1205.

(65) Zelenyuk, A.; Imre, D. Aerosol Sci. Technol. 2007, 41, 112-124.

(66) Zhang, C.; Thajudeen, T.; Larriba, C.; Schwartzentruber, T. E.; Hogan, C. J. Aerosol Sci. Technol. 2012, 46, 1065-1078.

(67) Martin, S. T. Chem. Rev. 2000, 100, 3403-3453.

(68) Biskos, G.; Russell, L. M.; Buseck, P. R.; Martin, S. T. Geophys. Res. Lett. 2006, 33, L07801 DOI: 07810.01029/02005GL025199.

(69) Biskos, G.; Paulsen, D.; Russell, L. M.; Buseck, P. R.; Martin, S. T. Atmos. Chem. Phys. 2006, 6, 4633-4642.

(70) Biskos, G.; Buseck, P. R.; Martin, S. T. J. Aerosol Sci. 2009, 40, 338-347.

(71) Katsyuba, S. A.; Dyson, P. J.; Vandyukova, E. E.; Chernova, A. V.; Vidiš, A. Helv. Chim. Acta 2004, 87, 2556-2565.

(72) Katsyuba, S. A.; Zvereva, E. E.; Vidis, A.; Dyson, P. J. J. Phys. Chem. A 2007, 111, 352-370.

(73) Snyder, R. G.; Strauss, H. L.; Elliger, C. A. J. Phys. Chem. 1982, 86, 5145-5150.

(74) MacPhail, R. A.; Strauss, H. L.; Snyder, R. G.; Elliger, C. A. J. Phys. Chem. 1984, 88, 334-341.

(75) Tait, S.; Osteryoung, R. A. Inorg. Chem. 1984, 23, 4352-4360.

(76) Talaty, E. R.; Raja, S.; Storhaug, V. J.; Dölle, A.; Carper, W. R. J. Phys. Chem. B 2004, 108, 13177-13184.

(77) Heimer, N. E.; Del Sesto, R. E.; Meng, Z.; Wilkes, J. S.; Carper, W. R. J. Mol. Liq. 2006, 124, 84-95.

(78) Höfft, O.; Bahr, S.; Kempter, V. Langmuir 2008, 24, 1156211566.

(79) Dieter, K. M.; Dymek, C. J.; Heimer, N. E.; Rovang, J. W.; Wilkes, J. S. J. Am. Chem. Soc. 1988, 110, 2722-2726.

(80) Hitchcock, P. B.; Seddon, K. R.; Welton, T. J. Chem. Soc., Dalton Trans. 1993, 2639-2643.

(81) Jeon, Y.; Sung, J.; Seo, C.; Lim, H.; Cheong, H.; Kang, M.; Moon, B.; Ouchi, Y.; Kim, D. J. Phys. Chem. B 2008, 112, 4735-4740.

(82) Gurnett, B.; Williams, D. Structure of water and aqueous solutions. In Proceedings of the International Symposium; Luck, W. A. P., Ed.; Verlag Chemie/Physik Verlag: Weinheim, Germany, 1974; p 206.

(83) Zhang, L. Q.; Xu, Z.; Wang, Y.; Li, H. R. J. Phys. Chem. B 2008, $112,6411-6419$.

(84) Horvath, S.; McCoy, A. B.; Elliott, B. M.; Weddle, G. H.; Roscioli, J. R; Johnson, M. A. J. Phys. Chem. A 2010, 114, 1556-1568.

(85) Rilo, E.; Pico, J.; Garcia-Garabal, S.; Varela, L. M.; Cabeza, O. Fluid Phase Equilib. 2009, 285, 83-89.

(86) Bahadur, R.; Russell, L. M. Aerosol Sci. Technol. 2008, 42, 369376.

(87) Bahadur, R.; Russell, L. M. J. Chem. Phys. 2008, 129, 094508.

(88) Ramos-Cordoba, E.; Lambrecht, D. S.; Head-Gordon, M. Faraday Discuss. 2011, 150, 345-362.

\section{NOTE ADDED AFTER ASAP PUBLICATION}

This paper was published on the Web on August 30, 2012. Changes have been made in equation 2 and the corrected version was reposted on September 13, 2012. 